SERVING IMMIGRANT FAMILIES: USING KNOWLEDGE TRANSLATION TO INFORM A FAMILY APPROACH IN THE SETTLEMENT SECTOR

by

Tania Dargy, B.Sc., McGill University, 2014

\author{
A Major Research Paper \\ presented to Ryerson University \\ in partial fulfillment of the requirements for the degree of \\ Master of Arts \\ in the Program of \\ Immigration and Settlement Studies
}

Toronto, Ontario, Canada, 2017

(C) Tania Dargy, 2017 


\section{AUTHOR'S DECLARATION FOR ELECTRONIC SUBMISSION OF A MAJOR RESEARCH PAPER (MRP)}

I hereby declare that I am the sole author of this Major Research Paper. This is a true copy of the MRP, including any required final revisions.

I authorize Ryerson University to lend this MRP to other institutions or individuals for the purpose of scholarly research.

I further authorize Ryerson University to reproduce this MRP by photocopying or by other means, in total or in part, at the request of other institutions or individuals for the purpose of scholarly research.

I understand that my MRP may be made electronically available to the public. 


\title{
Serving immigrant families: Using knowledge translation to inform a Family Approach in the settlement sector
}

\author{
Tania Dargy \\ Master of Arts 2017 \\ Immigration and Settlement Studies \\ Ryerson University
}

\begin{abstract}
Research studies show that the family is an integral dimension of newcomers' immigration and settlement experiences. Findings from a recent project on the integration trajectories of immigrant families shed light on the ways families support each other and the social factors of immigration. Still, immigration policy, federal data collection and measures, as well as settlement services rely on an individualistic conceptualization of newcomers with insufficient regard for their social realities. Preliminary consultations with partner settlement agencies in the Greater Toronto Area reveal there is a need to incorporate the family/social dimension in their services. Using the Knowledge Translation method, academic knowledge was transferred into a practical position paper for Immigration, Refugees and Citizenship Canada settlement policymakers. Through ongoing collaboration with the partners, the pillars of a Family Approach for the settlement sector were developed. Five key practical recommendations for its implementation are presented to policy-makers in the paper.
\end{abstract}

Key words: immigrant families, social networks, knowledge translation, family approach, family support, settlement services, settlement policy. 


\section{Acknowledgements}

I wish to acknowledge my partners from the non-profit settlement sector on this project: Diane Dyson, Director of Research and Public Policy at WoodGreen Community Services, and Josie DiZio, Senior Director of Planning and Program Development at COSTI Immigrant Services. I thank them for their precious collaboration and special investment in the project alongside their multiple responsibilities within their organizations. Their input and professional expertise were central to the development of this paper and provided an indispensable community settlement perspective to inform practical recommendations.

Josie DiZio was instrumental in establishing contact with government decision-makers for dissemination of this paper.

This project was made possible thanks to my research supervisor, Dr. Harald Bauder, who facilitated my involvement in the Integration Trajectories of Immigrant Families Project and introduced me to the settlement partners. His guidance and support are profoundly appreciated.

Lastly, I am grateful to Dr. Mehrunisa Ali who embraced my ideas and helped me in the development of my research project.

I dedicate this paper, the culmination of my most important work, to my husband, my sister, and my parents, who have provided me with their unwavering support, in all forms, throughout the completion of my master's. They have been lasting sources of inspiration, encouragement and motivation in all my life accomplishments, with many more to come. I am fortunate to call them my family. 


\section{Table of Contents}

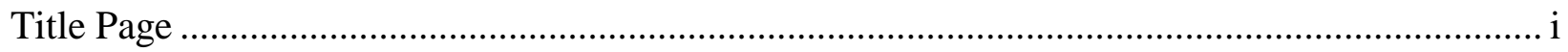

Author's Declaration for Electronic Submission of a Major Research Paper (MRP) ....................ii

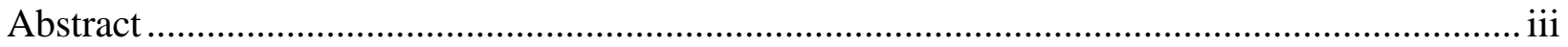

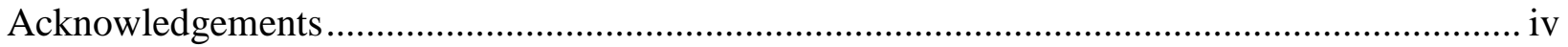

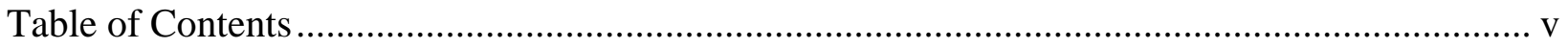

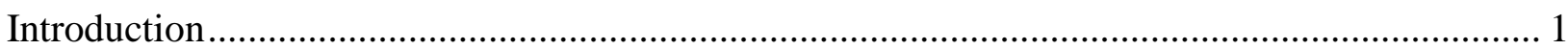

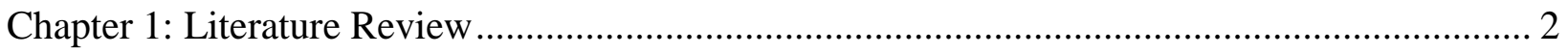

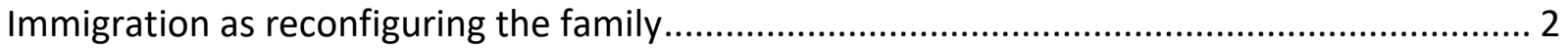

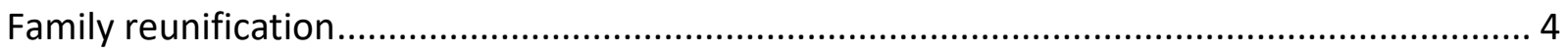

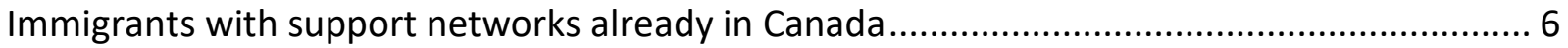

The new social support networks of immigrants in Canada.................................................. 8

The individualistic framework of policy and settlement services............................................ 10

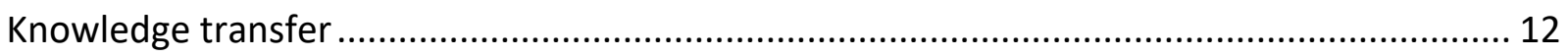

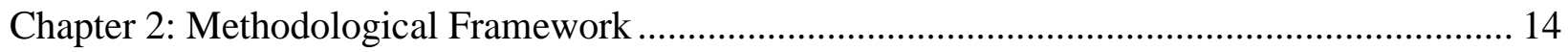

Significance of the Research and Conceptual Framework.................................................... 14

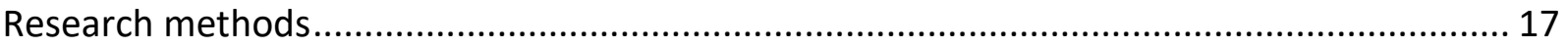

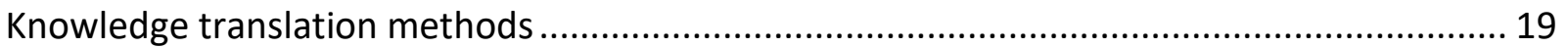

Target audience and dissemination .................................................................................. 24

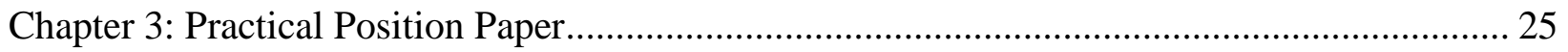

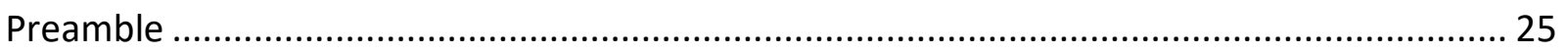

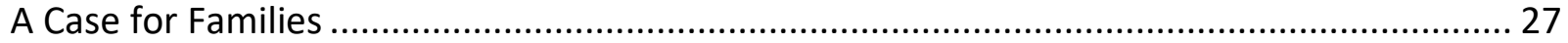

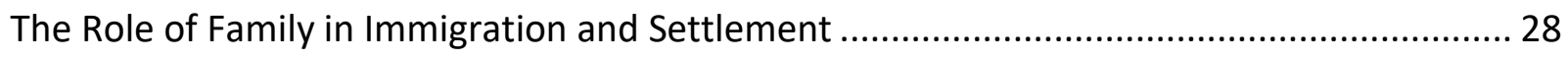

Immigration Policy Impacts on Family Structure ................................................................ 29 


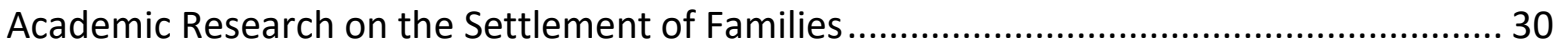

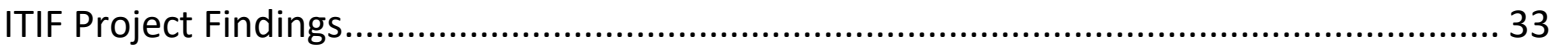

Current Service Framework in Settlement.................................................................. 40

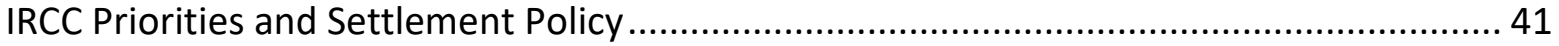

Settlement Organization Service Agreements ..................................................... 42

Towards Evidence-based Settlement Policy................................................................ 43

Proposing a 'Family Approach' in Settlement ............................................................. 45

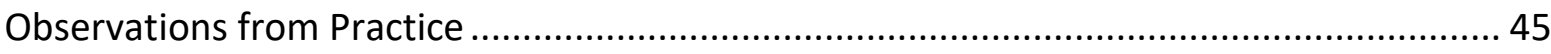

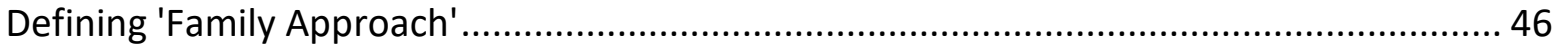

Practical Recommendations for Settlement ...................................................................... 48

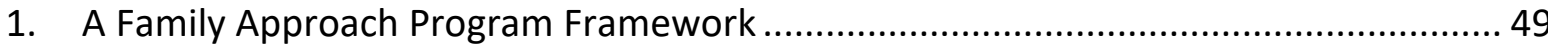

2. Identification of Family-Related Needs................................................................ 50

3. iCare Database and Family Unit Analysis ................................................................ 54

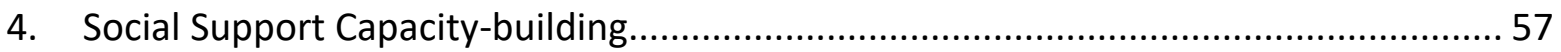

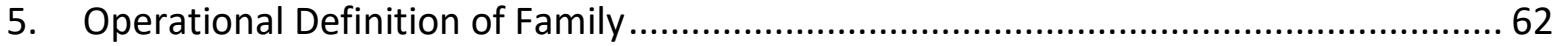

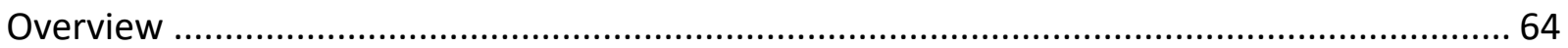

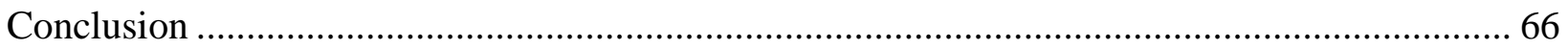

Appendix 1 - Preliminary questions for first consultation meeting .................................... 67

Appendix 2 - Executive Summary (English Version) ....................................................... 68

Appendix 3 - Résumé (Version Française) ................................................................... 70

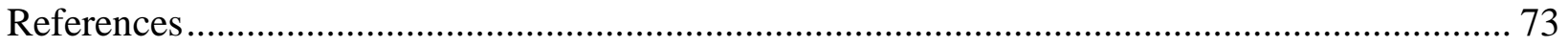




\section{Introduction}

Academic research studying the settlement experiences of immigrant families and their support networks in Canada has uncovered empirical evidence that the settlement process is profoundly familial/social. The Integration Trajectories of Immigrant Families project (ITIF hereafter), spearheaded by the Ryerson Center for Immigration Studies, also contributes to elucidate the ways in which immigrants situate themselves within family networks and how these influence settlement decisions. This important knowledge base on immigrant family networks and socially-mediated settlement experiences has not been bridged to the settlement sector to inform policy and practice, settlement program design and outcome measurement. The settlement sector relies on an individualized framework that does not reflect immigrant families' realities.

At the same time, "[Higher level decision-makers at Citizenship and Immigration Canada (now IRCC)] have indicated that they are open to working with sector organizations to build a client-centered approach to immigrant settlement program design and service delivery" (OCASI, 2010, p.4). My project is a response to this practical problem - it aims to gather the academic research on the settlement of immigrant families in Canada and transfer it into practical use to inform an evidence-based client-centered approach to settlement sector practices. The resulting product is a position paper to be presented to Immigration, Refugees and Citizenship Canada (IRCC hereafter) settlement policy-makers. I will begin with a literature review leading into the practical research question guiding this project, followed by a detailed methodology section. The integral position paper is imbedded thereafter. 


\section{Chapter 1: Literature Review}

Recent research on immigration demonstrates that the experiences and needs of newcomers cannot be divorced from the web of interconnections they share with family and social networks. While there are still too few studies on immigrant families as units (Cottrell \& Vanderplaat, 2011), there is sufficient literature to argue that in order to serve the needs of newcomers settling in Canada, a family approach, rather than a limited individual approach, must be utilized. Yet, a close review of the literature demonstrates that academics have omitted to ensure their findings are translated into practical application for the settlement sector. As a result, there is a gap between academic work demonstrating the importance of situating immigrants within families and settlement sector practice and funding which treats immigrants as discrete individual units. This section will review the literature on the family/social networks of newcomers and highlight the discrepancies with settlement sector structures. The concept of Knowledge Translation will be introduced as a useful approach to close the gap between research and practice.

\section{Immigration as reconfiguring the family}

Immigrants who have been selected to become permanent residents of Canada are permitted to be accompanied by their spouse/common-law partner/conjugal partner and their unmarried children below 19 years old (IRPR, SOR/2015). Immigration policy is shaped by "a 'traditional' understanding of family roles" (Strasser, Kraler, Bonjour, \& Bilger, 2009, p.175) which privileges the nuclear family model (Baldassi, 2007) and renders most other relationships inadmissible. Yet, for many immigrants, extended family constituted essential forms of support in their country of origin (Strasser et al., 2009). Thus, immigration policy acts as a powerful mechanism which restructures immigrant families (Satzewich, 1993). Families are compelled to 
reorganize themselves and make difficult decisions when faced with the context afforded by the new destination-country. For example, Chinese immigrant couples' decision to leave their child with an elder in China is a fundamental restructuring of the family that is a necessary coping mechanism against the backdrop of their economic strain and lack of social support in Canada (Salaff \& Greve, 2004). Due to circumstances of settlement like labor market expectations and the lack of affordable services to sustain family life in parallel with dual-career goals, immigrant families make large sacrifices (Salaff \& Greve, 2004).

In a qualitative study with families from the economic immigration category, researchers found that while male and female spouses may have similar education levels and labor market achievements in their country of origin, it is likely that the female spouse may sacrifice her first Canadian work experience (altogether or in terms of expected wage/skill) in order to support the career chances or re-skilling of her spouse (Phan, Banerjee, Deacon, \& Taraky, 2015). The families explain that the availability of extended family in their home country had facilitated the dual-career aspirations of the couple. In its marked absence in Canada, the spouse often deferred her career objectives to assume child care responsibilities (Phan et al., 2015). Other studies confirm that a reduced family network for nuclear immigrant families in Canada results in a more pronounced gendered integration with women having less opportunities to pursue their career goals (Bragg \& Wong, 2016; Creese, Dyck, \& McLaren, 2008).

Parenting roles are also altered through the process of settling in a new country. Interviews with immigrant families reveal that parent-teen conflicts arise as a result of 'parenting across cultures' and the identity struggles of family members (Cottrell \&Vanderplaat, 2011). Parents express great stress and concern over their children growing up without an extended family network in Canada (Bragg \& Wong, 2016). Thus, immigration policy and settlement 
experiences reconfigure the structure of family, living arrangements, family dynamics, roles, identity, relationships, and expectations of support (Cottrell \& Vanderplaat, 2011). Therefore, immigration, on a very profound level, is a family experience (Cottrell \& Vanderplaat, 2011). Family reunification is often mentioned as a long-term goal to reconstitute family and acquire more support (Phan et al., 2015).

\section{Family reunification}

Telegdi's article (2006) provides a useful overview of current policies on family reunification based on the 2001 Immigration and Refugee Protection Act (IRPA) which is still in effect today. Family reunification is the immigration policy that permits immigrants to sponsor designated family members to join them permanently in Canada. Eligible family members for sponsorship are spouses, common-law or conjugal partners, parents and grandparents, unmarried children below the age of 19 and related orphaned dependent children below 18 (IRPR, SOR/2002; Telegdi, 2006). Over the years, increased applications for family reunification prompted the government to instate an annual quota system, resulting in a backlog of applications and long processing delays (Telegdi, 2006).

Vanderplaat, Ramos, and Yoshida (2012) emphasize that a large part of the debate on family reunification is centered on the idea that sponsoring family members is beneficial only to the individual sponsor and not to the wider society. Yet, family class sponsorship was found to be mutually beneficial to the integration of the sponsor, the sponsored, and to society in general (Bragg \& Wong, 2016; Creese et al., 2008). Bragg and Wong (2016) found contributions such as a grandparent providing free childcare and moral support to the family have significant economic returns such as facilitating the mother's capacity to enter the workforce. This reinforces the view 
that family sponsorship is a win-win-win cause and that family class immigrants make important contributions to their families in Canada as well as society.

Although the definition of who constitutes family differs between individuals and cultures, most immigrants interviewed in studies include adult children, siblings, grandparents and parents, cousins or other relationships as family members and important sources of support (Bragg \& Wong, 2016; Ebaugh \& Curry, 2000; Strasser et al., 2009). These familial ties are not eligible for family reunification in Canada today (some were until 1993) (DeShaw, 2006). Studies on extended families who managed to bypass family reunification and immigrate to Canada through separate channels provide crucial information on the social support afforded by members such as siblings, adult children and cousins who are not eligible for sponsorship. These families are able to support each other and coordinate their settlement plans amongst more people, reducing the need for the core nuclear family to bear all sacrifices (Creese et al., 2008). The restrictions on family reunification have important consequences on immigrants' settlement. For instance, respondents revealed that in the absence of parents and grandparents, they felt responsible to care for their parents abroad. They sent large sums in remittances and had to disrupt stable employment because of emergency travel (Bragg \& Wong, 2016).

Researchers posit that family reunification is key to the integration of immigrants and that failing to see the social contributions of family, including extended family, also has economic costs and leads to poor policy decisions (Bragg \& Wong, 2016; Strasser et al., 2009; Vanderplaat et al., 2012). Research on the contributions of family class immigrants is lacking and therefore largely underestimated (Bragg \& Wong, 2016). Still, the above examples demonstrate how quantitative and qualitative studies can complement each other to inform our understanding of immigrant families' experiences. With current restrictions on family 
reunification, networks with close friends and family in the country of origin are severely disrupted due to immigration (Hynie, Crooks, \& Barragan, 2011; Strasser et al., 2009).

\section{Immigrants with support networks already in Canada}

Regardless of immigration category, all immigrants experience a rupture of their social/family networks from their country of origin, including extended family, as a result of immigration (Guruge et al., 2010; Salaff \& Greve, 2004; Strasser et al., 2009). Thanks to communications technology, transnational social relationships can be maintained. In many studies on immigrant families, the support that continues to be provided by family members who live in the country of origin is not addressed. Transnational ties can offer valuable social and financial support which facilitate the settlement outcomes of immigrant families (Phan et al., 2015). Nonetheless, their physical absence is strongly felt (Bragg \& Wong, 2016). Therefore, immigrants attempt to re-build their social networks once in Canada, starting with relatives and friends they already know (Bergeron \& Potter, 2006; Hynie et al., 2011; Simich, Beiser, \& Mawani, 2003).

As many as $87 \%$ of immigrants report having friends, relatives or both living in Canada at the time of their arrival (Bergeron \& Potter, 2006). Bergeron and Potter (2006) conducted a quantitative analysis of the Longitudinal Survey of Immigrants to Canada (LSIC) which demonstrated that immigrants draw on their social capital (i.e. their family connections in Canada) during their initial settlement period. This concurs with the accepted notion that migration decisions are made at the group level and social/family networks directly influence when and where individuals migrate (Boyd, 1989). For example, Simich et al. (2003) found that several government-assisted refugee women who were pre-assigned to destination cities across Canada by immigration officials decided to either change their destination city from the airport 
or to engage in secondary migration to settle in proximity of their existing support systems in Canada. Even when they arrived as an intact nuclear family unit, immigrant women report feeling lonely, and needing extended relatives to be happy, so they moved as close as possible to them (Lynam, 1985; Simich et al., 2003).

Respondents agree that moving near an existing support system strengthens the social ties they share (Bergeron \& Potter, 2006; Simich et al., 2003). Most surveyed newcomers reported family and friends as either the first or second most important provider of assistance regardless of the settlement goal (Bergeron \& Potter, 2006). Responses consistently showed that the presence of family facilitates immediate settlement (housing, employment, health) (Bergeron \& Potter, 2006) and provides stability for the pursuit of long-term settlement goals (Creese et al., 2008). Researchers assert having family and/or relatives in Canada is the most important predictor of immigrant success and integration (Creese et al., 2008; Lewis-Watts, 2006; Telegdi, 2006).

Creese, Dyck, and McLaren (2008) conducted a comparative qualitative longitudinal study of the settlement experiences of immigrant families in Canada, two nuclear families and two extended families. They found that the nuclear families without existing friends or relatives in Canada had fewer resources for integration, employment and re-skilling (Creese et al., 2008). In contrast, the families with extended kin were able to mobilize resources through their ability to pool funds, share accommodation, and share child care, which allowed them to pursue longterm goals (Creese et al., 2008). The study suggests that extended families may be the key to integration in the precarious and unstable circumstances of early settlement. Family networks, when available, provide multiple forms of support as well as a strong reciprocity and are consequential to overcoming these challenges (Bergeron \& Potter, 2006; Bragg \& Wong, 2016; 
Creese et al.,2008; Hynie et al., 2011). Immigrant families who enjoy the luxury of having an extensive network of relatives in Canada are less likely to pursue other forms of social support networks (Creese et al., 2008). Not all immigrants, though, have relatives in Canada when they arrive.

\section{The new social support networks of immigrants in Canada}

Some immigrants have few or no relatives or friends in Canada when they arrive. This is the case of $25 \%$ of resettled refugees (Bergeron \& Potter, 2006). Moreover, newcomers from Russia and Korea are significantly less likely to know anyone in Canada upon arrival (Bergeron \& Potter, 2006). In those cases where immigrants have no existing support network in Canada, they are compelled to form rapidly new social connections in order to offset the absence of family and to facilitate settlement (Creese et al., 2008; Hynie et al., 2011; Lynam, 1985). The formation of social networks is itself a settlement strategy and means of coping with a reduced support system as a newcomer in Canada.

Social networks are formed through many different channels, from the local neighborhood, workplace, settlement organization and community activities, to language classes, volunteerism, and religious attendance (Hynie et al., 2011; Rose, Carrasco, \& Charbonneau, 1998; Wang \& Handy, 2014). Immigrants' social networks are more ethnically homogenous as compared with native-born Canadians (Kazemipur, 2006) and some studies show co-ethnicity is an important characteristic of immigrants' social ties (Hynie et al., 2011; Rose et al., 1998; Simich et al., 2003). The common life experiences shared with co-ethnic members provides an immediate sense of emotional closeness through validation which can lead to deep friendships (Lynam, 1985; Rose et al., 1998; Simich et al., 2003). Interviewees were clear that co-ethnic 
support was precious because it was culturally relevant, providing continuity of references between their country of origin and Canada (Simich et al., 2003).

However, research shows that the overall co-ethic community tends not to be as helpful and reliable as newcomers hoped because they are themselves overburdened with their own hardship (Cottrell \& Vanderplaat, 2011; Hynie et al., 2011; Phan et al., 2015). Additionally, in cases in which immediate family members are not emotionally supportive or in cases of marital problems, women avoid exposing their problems to those members and prefer formal sources of support such as settlement counselors or health care professionals (Hynie et al., 2011). In the study by Rose, Carrasco, and Charbonneau (1998), 50\% of refugee women preferred formal sources of support by social workers, nurses and counselors for complex issues rather than family, even if they had formed close friendships. Women who lack informal types of support are more likely to access settlements agencies for instrumental, informational and emotional needs (Bergeron \& Potter, 2006; Hynie et al., 2011). Typically, they try to find a settlement worker of the same ethnic background which makes the relationship more meaningful and also "blurred the boundary between formal and informal support" (Hynie et al., 2011, p.41).

Thus, the argument for a family approach poses a fundamental conceptual question: what is family and for who? Family is defined differently by different individuals, cultures and societies (Frideres \& Madibbo, 2013). As explained by Holstein and Gubrium (1999), "the essence of family is found in the way family is used, not in conventional or idealized social forms..." (p.7) because "...there is no 'given' relationship between reality and representation" (p.17). It is only after we understand family as the chosen source of support that we can begin to situate the needs of immigrants. The different members of immigrants' social networks offer diverse forms of support. Collective levels of belonging such as social networks, family, and 
other groups inform identities (Hogg \& Abrams, 1999) and settlement decisions. Thus, many researchers argue that using a family approach in immigration research and services is necessary to address the needs of immigrants (see Cottrell \& Vanderplaat, 2011 for a review).

In sum, a review of the literature on immigrant families makes a strong case for understanding the settlement experience of immigrants as being deeply interconnected with family, extended relatives and even close friends or service providers. Immigrant families are reconfigured through the immigration and settlement process, leading them to make large sacrifices and to experience changes in gender and parenting roles, living arrangements, and expectations of support. It follows that if the settlement sector is mandated to serve immigrants' needs, they must use a service framework that situates immigrants within family/social realities. However, scholars' findings on the impact of family on the settlement experience have remained within the academic sphere. Many scholars have neglected to transfer this knowledge to the settlement sector, effectively informed policy, or shared their work with those who provide services to immigrants, resulting in these sectors continuing to operate on individualistic principles.

\section{The individualistic framework of policy and settlement services}

The current immigration and settlement framework relies on a conceptualization of newcomers as individual units, whose value is determined based on their presumed capacity to be economically self-sufficient or not (Creese et al., 2008). The Canadian immigration system classifies immigrants into three categories: economic, family class, and refugee (IRPA, 2001). In every immigration stream, policy requires that one person is designated as the principal applicant and accompanying family members are labeled dependents (IRPA, 2001). The principle of dependency extends to family reunification. In this category, sponsored family member(s) are 
permitted to immigrate to Canada by virtue of a definition of the family that presumes their dependency in relation to a sponsor (Strasser et al., 2009). Simply put, the Canadian immigration system individualizes immigrant families by lumping both accompanying and sponsored family members into the dependent category and assigning them to their principal applicant or sponsor.

Furthermore, policy frames family immigration as a unidirectional process whereby family members are reliant on the sponsor or principal applicant for settlement. This only serves to reinforce assumptions of dependency that policy attributes to family members. The dependency framework fails to account for the support that family members provide by virtue of immigrating to Canada as well as their long-term contributions (Strasser et al., 2009).

Vanderplaat et al. (2012) write that "qualitative studies focusing on family class immigrants have not been conducted in conjunction with, or successfully linked to large scale quantitative data, limiting their capacity to be policy informative" (p.81). Furthermore, the individualistic policy framework overlooks the needs of the family as a unit and makes it impossible to accommodate individuals as family members (Creese et al., 2008). This framework permeates immigration statistics, integration measures and settlement services.

Almost all statistics on immigration available in Canada are at the individual level (Kustec, 2006). Statistics on the integration outcomes of newcomers are also predominantly measured at the individual level, often solely in economic terms (Vanderplaat et al., 2012). The Canadian government, in charge of setting settlement program funding priorities, then uses these individual level statistics to make funding decisions. Government funding is the primary source of financial support for Immigrant Settlement Agencies (ISAs) to offer services to newcomers (Mukhtar et al., 2016). The strict, results-oriented program funding contracts limit the flexibility of ISAs to undertake new service initiatives or adapt programming for specific needs (Mukhtar et 
al., 2016). Accordingly, government funding of settlement programs is determined by quotas of individual participants in programs and service needs are determined based on the immigration status of individual clients (OCASI, 2010). Outcome assessments of these programs are also tabulated at the individual level (CIC, 2011).

The most widespread program mandate of settlement organizations funded by IRCC is a Needs Assessment and Referral service which consists of a "formal identification of client needs and connect[ing] them and their family to available supports" (IRCC, 2017a). Needs assessment of newcomers by settlement workers lacks a consistent framework to situate needs and resources of immigrants within social networks and families. The role of family relationships is only addressed for specialized needs such as domestic violence or family dysfunction/crisis (IRCC, 2017a). In other words, as Satzewich notes, "immigrants' commitment and practical need for family is characterized by the state as 'irrational' and 'pathological'" (Satzewich, 1993, p.315).

\section{Knowledge transfer}

While settlement workers are aware of the importance of serving immigrants as members of families and social networks to address their needs (COSTI and WoodGreen, personal communication), there is no agreed-upon framework to achieve this, nor is this aspect reflected in settlement program design and statistics. This systematic individualized structure fails to situate immigrants as members of families. For the settlement sector to be informed by a family approach, research evidence from academia must be bridged into practice. However, most researchers of family settlement have not taken this important step. Shields and Evans (2012), write that this is symptomatic of a great problem "in that traditional sources of academic dissemination for research findings have not been effective at reaching audiences beyond the scholarly community" (p.255). 
According to Shields et al. (2015), Knowledge Transfer/Translation (KT) is a methodology through which knowledge from one stakeholder in the sector can be effectively translated to another stakeholder. As such, forging relationships between different stakeholders of the sector is central to KT (Shields et al., 2015). The primary criterion to determine the relevance of a KT project is that there is substantial agreement in the research community and much empirical support to justify the translation of this knowledge (Straus, Tetroe, \& Graham, 2009). The above literature review of immigration and settlement as a family experience substantiates the call for a KT effort between academic research and the settlement sector, which includes decision-makers and service providers.

According to the authors, KT is a two-step process of knowledge implementation/ mobilization followed by knowledge transfer/translation (Shields et al., 2015). Knowledge implementation/mobilization is more about gathering evidence and information pending the transfer. For example, the authors describe the Symposium held by the CERIS project as being a particularly fruitful site of exchange for knowledge mobilization (Shields et al., 2015). The actual knowledge transfer consists of translating the knowledge into an accessible format to ensure that it successfully 'transfers', and that it is relevant and practical to the stakeholder. In the case of the CERIS project, the evidence was compressed into two-page summaries which made it accessible to policy-makers (Shields et al., 2015). The key challenge for any KT project is determining how to go about the knowledge transfer. Thus, the guiding research question for this project is the following: using Knowledge Translation (KT), how can academic research on the importance of situating immigrants within families be transferred into a practical family/social networks approach and framework for settlement services, and challenge the current individualistic structure of program design, funding and policy? 


\section{Chapter 2: Methodological Framework}

\section{Significance of the Research and Conceptual Framework}

Consultations with settlement organizations (COSTI \& WoodGreen, personal communication) confirm there is a need to incorporate a social networks/family approach in client services. This research project helps settlement organization achieve this goal through translating academic knowledge into practical application for the settlement sector. Specifically, the purpose of the project is to produce a position paper which informs IRCC settlement decision-makers and provides recommendations for the implementation of a Family Approach, which better addresses the needs of newcomers.

In my view, findings on immigrant families speak as the epistemic voice of immigrants to better inform the services that concern them directly. I undertook this project with the hope that immigrant families may benefit from this knowledge. Accordingly, this KT project informs a needs-driven and outcome-oriented effort to "foster new (or strengthen existing) skills and credentials which directly contribute to better operations, services and settlement outcomes for newcomer clients" (IRCC, 2017a).

This project entails that I be mindful of subjective identities, inequalities and power relations that are embedded within families and social groups (Creese et al., 2008). Households should not be conceptualized as homogenous entities; families are fluid, inseparable from internal dynamics, and changing depending on needs (Creese et al., 2008; Satzewich, 1993). For example, gender identity, as shown in how some parents disagreed with their daughters' behaviour in Cottrell and Vanderplaat's interviews (2011) impact daughters' family experiences of identity management by family members and ethnic communities as women. 
Furthermore, the literature review above has demonstrated that support from an immediate family member or a relative is not always preferred. Some research has uncovered cases where immigrants purposely dissociate themselves from their families, as was described by queer refugees interviewed in Philips' (2016) research. For these individuals, 'family' was often re-constructed to include other queer refugees with similar refugee experiences. This phenomenon is reminiscent of Weston's (1991) work on 'chosen families' which showed gays and lesbians in the 1980's redefined institutional and ideological kinship to shape families of their own that included close friendships, a lover or a co-parent.

Highlighting alternative definitions of family that exist for newcomers must be done critically and sensitively when advocating for a family approach in research and settlement. Care should be taken to avoid Western ethnocentric bias that casts family forms in negative and 'Othering' terms when they do not fit the Western traditional nuclear model of family (Satzewich, 1993). Thus, this research project espouses a subjective, flexible and fluid notion of family that avoids pre-determined definitions and approves the validity of a family approach insofar as immigrants themselves define who is family as well as their relationships within it.

As the person conducting this research, it is important to also be reflexive of how my identity and experiences filter my work (Locke, Silverman, \& Spirduso, 2004). Being married to a non-Canadian national and having gone through the process of family reunification, I personally understand the complexities of family separation as well as being a support in the settlement of a newcomer first-hand. While I did not experience immigration myself, I am one of the deeply interconnected relations of family support that influenced my husband's settlement in Canada. This personal life experience motivates me to pursue research on the needs of newcomer families. Furthermore, I have worked as a settlement worker for immigrant women for two years 
which enriches my research because I have a solid understanding of the non-profit settlement sector myself.

In this research project, the pragmatic and transformative perspectives are used as the core paradigms. A pragmatic project is 'real-world' practice oriented (Creswell, 2013). The practical goal dictates the research method to be used rather than a pre-determined paradigm (Creswell, 2013; Mackenzie \& Knipe, 2006). According to Kvale's (1995) concept of pragmatic validity, a knowledge project is 'valid' insofar as the actions/uses that emerge from it are effective. In this manner, knowledge is validated by successful application. Building on this concept, my research project seeks to move beyond a 'communicative approach' (Kvale, 1995) where I would simply communicate recommendations to the settlement sector without consulting them. This has already been done by some scholars such as Cottrell and Vanderplaat (2011). Rather, to ensure pragmatic validity, this project used a partnership approach with settlement sector professionals through multi-level consultations. The concept of pragmatic validity fits nicely with the KT methodology, which "requires an ongoing dialogue with users to help transform and shape information" (Shields \& Evans, 2012, p.254). As Smith observes, academics and service providers/decision-makers 'think differently' because of the demands, purpose, and culture of their work (Smith, 2007 as referenced in Shields \& Evans, 2012). Therefore, a translation effort requires a back-and-forth partnership to ensure validity.

The project also espouses the transformative perspective, because it is collaborative and change-oriented (Creswell, 2013). It is my hope that the document produced through this knowledge translation effort will be used by stakeholders to improve services for immigrant families. Making changes in federal settlement policy can take a great deal of time. Even if IRCC decision-makers are receptive to my research, actions cannot be expected to follow immediately. 
However, fostering discussion around the topic can be a transformative step towards eventual change. The position paper can also become a tool used by settlement agencies to advocate for a family approach in the sector and create momentum for improvements.

\section{Research methods}

According to the IRCC settlement priorities webpage, the production of knowledge by ISAs through research is a key strategy to generate evidence-informed policy and settlement practices (IRCC, 2017). Shields and Evans (2012) note that there has been a growing interest on the part of policy and decision-making government representatives to inform policy and practice by evidence. Specifically, IRCC calls for project proposals inspired by a knowledge mobilization/translation approach where research on the settlement experiences of immigrants can lead to improved settlement service delivery. It is written that such a project should aim to "deliver results in the area of knowledge translation and mobilization to help the settlement sector and practitioners benefit from relevant research and knowledge products" (IRCC, 2017).

My KT project draws significantly on the findings from the Integration Trajectories of Immigrant Families (ITIF) project. The ITIF project began in 2014; it is an academic-community partnership project funded by the SSHRC Partnership Development Grant. The ITIF project is spearheaded by the Ryerson Center for Immigration Studies and involves multiple academic researchers on the team ${ }^{1}$. The community partners of the ITIF project are two established ISAs in the Greater Toronto Area: COSTI Immigrant Services and WoodGreen Community Services. Representatives from COSTI and WoodGreen contributed extensively to the project, assisting with the conceptualization of the project and participant recruitment.

\footnotetext{
${ }^{1}$ For more information on the ITIF project, see the project website: http://www.ryerson.ca/immigrant families/
} 
The ITIF project team collectively conducted the collection of data. Empirical data was collected through qualitative interviews with 28 participants (23 families) who had immigrated to Canada through the Economic Class between 5 to10 years ago. The participants resided in the Greater Toronto Area and were capable of communicating in English. The interviews were done over two sessions with each family, each lasting approximately one hour. The first interview involved questions regarding the family's status and social networks in the country of origin, the reasons for the decision to migrate, the settlement challenges faced on arrival, and the sources of support they used. Participants were also asked to draw a socio-gram ${ }^{2}$ of their family. During the second interview, participants were asked to define their relationships with the family members they chose to include on their socio-gram, the evolution of the relationship over time, how each person provided support, and how settlement challenges affected the family. Subsequently, each researcher of the ITIF project team analyzed the data with a particular research focus. Dr. Ali and her team conducted a qualitative analysis of the interview transcripts with a special focus on social support.

In January 2017, I became involved in the ITIF project as a graduate research assistant to Dr. Ali. The findings of our team are due to be published in a chapter (Ali, Valade, \& Dargy, forthcoming) in the forthcoming edited volume Migration is a Family Affair (Bauder, forthcoming). With the guidance of my supervisor, Dr. Harald Bauder, also the ITIF research lead, I decided to draw on the ITIF project for my graduate Major Research Paper (MRP). The

\footnotetext{
${ }^{2}$ Socio-grams are a visual representation of one's own social/family support networks. The self is placed at the center and family members are connected by tracing a line outward and writing their name. Stronger ties are represented closer to the self or by a thicker line while weaker ties are drawn further from the self and with a thinner/dotted line.
} 
ITIF project presented a unique opportunity to bridge the gap between theory and practice in settlement, making my MRP a practical one.

The ITIF findings form the basis of evidence for my knowledge translation effort. They are particularly useful because they complement the existing body of academic literature on immigrant families. The ITIF project interview transcripts and socio-grams were made available to me. My knowledge translation project draws heavily on the secondary data from the ITIF project to illustrate how families/social networks inform settlement decisions. I use key citations taken from the interview transcripts to show the different subjective definitions of social network/family structures and to bring newcomer voices to the forefront.

\section{Knowledge translation methods}

Knowledge Translation refers to "The process by which a body of research knowledge is presented in multiple formats to practitioners and decision-makers. The... parties are engaged in a sustained, intensive, interactive process that results in a transformation of the knowledge to the purposes of the organization" (Kramer, 2002 as cited in Shields \& Evans, 2012, p.254). When conducting KT, all parties should benefit from the partnership. Shields et al (2015) emphasize that the government-dependent funding structure of not-for-profit organizations causes them to be over-stretched by a lack of resources and funding, whereby their capacity to invest time in research is incredibly limited. Therefore, translating knowledge which has already been collected by academic researchers is a cost-effective way for ISAs to generate evidence-based practice (Shields \& Evans, 2012).

ISAs are the only stakeholders in the settlement sector who have a direct, personal and long-standing relationship with immigrant communities and who hold the exclusive position of witnessing daily their lived experiences, which academics and policy-makers typically do not. 
Senior professionals within ISAs occupy the role of what Shields and Evans (2012) refer to as 'knowledge brokers'. As knowledge brokers, ISA decision-makers are involved in the development of practice for front-line staff, program design, as well as consultation and dialogue with IRCC funding and policy decision-makers. Therefore, in order to effectively translate academic research on immigrant families to policy-makers, their involvement in the project is necessary. Front-line service providers in ISAs also constitute important 'person knowledge banks' that must be tapped for the project to be useful and successful (Shields \& Evans, 2012).

For this project, a partnership was secured with two large ISAs whose input was critical. Neither I, as the researcher, nor the partners from the ISAs received funding for this particular project. I see this as a strength of this project, since it allowed ISA representatives to step out of the contractual/financial power imbalance in which they are typically caught when doing government-funded research projects (Shields \& Evans, 2012). This project did not require ethics approval because, as a member of the ITIF team, I was authorized to make use of the academiccommunity partnership. Furthermore, partners were asked about general settlement sector practice as representatives of settlement agencies, information that is widely available and discussed among practitioners and Local Immigration Partnerships (LIPs), not their own subjective experiences or opinions. As such, they were considered partners, or collaborators, not subjects or participants.

My primary partners (and knowledge brokers) on this project were Diane Dyson, Director of Research and Public Policy at WoodGreen Community Services, and Josie DiZio, Senior Director of Planning and Program Development at COSTI. The partnership was secured through the ITIF research project. I met the partners for the first time during the Ryerson University - Immigration is a Family Affair Workshop on February $14^{\text {th }}, 2017$, where the 
research team presented the preliminary results of the ITIF project. The principal investigator of the ITIF project Dr. Harald Bauder, who is also my MRP supervisor, proposed the potential partnership between myself, Ms. Dyson and Ms. DiZio. Shields and Evans (2012) write that trust and understanding are the foundation of a partnership and necessary for effective KT (Shields \& Evans, 2012). The longstanding partnership that WoodGreen and COSTI have with Ryerson University and their involvement in the ITIF project favored this trust.

The first step of Knowledge Translation is to transform the knowledge into a useful format before the transfer begins (Straus et al., 2009). This step is referred to as the Knowledge Mobilization (KM) stage when knowledge is gathered for the purpose of transfer (Shields \& Evans, 2012; Shields et al., 2015). The knowledge derived from the ITIF project was mobilized during the said workshop where the findings were presented to partners and collaborators. Ms. Dyson and Ms. DiZio were in the audience representing WoodGreen and COSTI as partners of the ITIF research project.

Second, the researcher must mobilize the different parties to find interest and use in the knowledge produced (Shields et al., 2015). According to Lomas (2000), "early and ongoing involvement of relevant decision makers in the conceptualization and conduct of a study is the best predictor of its utilization" (as cited in Shields \& Evans, 2012, p.254). The development of the project evolved through ongoing communication with Ms. Dyson and Ms. DiZio after the workshop in February. Although this KT partnership was lead entirely by me, a graduate student, settlement partners were highly invested in its success. The ITIF findings confirmed what settlement workers had been observing for a long time. Therefore, partners supported the transfer of this evidence to settlement policy-makers. They indicated that they are committed to 
incorporating a family approach in their services and willing to adapt their practices even if policy changes do not materialize from the project.

Through a group conference call (Ms. Dyson, Ms. DiZio, Dr. Bauder, \& myself) held on February $23^{\text {rd }}, 2017$, and subsequent feedback on a preliminary MRP outline, it was jointly decided that the format of the MRP would be a position paper with service recommendations for IRCC policy-makers. It was decided to primarily focus the KT project on the Needs Assessment and Referral settlement service. Furthermore, this position paper would represent the combined voice of both academic researchers and senior settlement practitioners. This format was recommended by the partners as a valuable means for dissemination and further translation to other audiences. The standard academic article format was discarded because they "are written primarily for very narrow [academic] audiences or peers almost always in highly discipline specific language", while "the use and impact value of getting research to bigger and broader audiences" is at the core of this project (Shields \& Evans, 2012, p.255). To overcome the typical 'academic jargon' (Shields \& Evans, 2012) and make the language and format accessible to nonacademics yet remain influential, the position paper format appeared most suitable.

In order to carry out this KT project, I, as the knowledge translator, had to become familiar with the structure of service delivery and program design currently in place in the partner ISAs. I consulted Ms. Dyson and Ms. DiZio to inquire about settlement services offered at WoodGreen and COSTI and how program design, services and outcome measurement are determined and bound by funding contracts they have with IRCC. I asked to have access to internal documentation that could supplement my project, such as documents on current needs assessment practices. 
Consultations with settlement partners were held between March and July 2017. A set of guiding questions was prepared prior to the first consultation meetings (see Appendix 1). The first consultation meetings were held separately. The meeting with Ms. Dyson was held in person on June $7^{\text {th }}, 2017$ in her office at the WoodGreen Community Services Danforth location in Toronto. The first consultation meeting with COSTI representatives was held in person at the COSTI North York Center on June $9^{\text {th }}, 2017$. Ms. DiZio organized for two other COSTI settlement professionals to be present at the meeting: Angela Girardo, Settlement Services Manager, and Mary Ibrahimi, Team Lead. Ms. DiZio participated in the meeting over speaker phone from the COSTI head office. The team provided me with documentation: excerpts from IRCC service agreements (including program accountability requirements ${ }^{3}$ ), Client Support Services (CSS) intake forms, and internal COSTI client assessment forms. As per my request, they also provided me with images of the Internal Contribution Agreement Reporting Environment (iCARE) platform for the Needs Assessment and Referral program and the Information and Orientation program. After the first round of consultations and an analysis of the documentation, I gathered notes on important preliminary findings. I developed a set of follow-up questions that were sent to the partners two weeks prior to the second consultation meeting. The second consultation meeting was held on July $14^{\text {th }}, 2017$ over conference call with both Ms. Dyson and Ms. DiZio. Five practical and relevant recommendations for the implementation of a Family Approach were developed for IRCC policy-makers.

Meetings were not audio-recorded and lasted approximately one hour each. During the meetings, I took as many notes as possible on our discussions. Immediately afterwards, I

\footnotetext{
${ }^{3}$ Accountability requirements are typically a form of data collection that service providers are responsible for, such as number of clients serviced, demographic information on clients, number of referrals, etc (CIC, 2011).
} 
organized the notes into meeting minutes, dividing them according to the questions I had prepared. The number of consultations with partner organizations was limited by the time constraints of the project. Prior to the first consultation meeting (during the project development phase) as well as after the second consultation meeting, I communicated with partners by e-mail through a collaborative back-and-forth process for clarifications or scheduling the meetings. Since they are extremely busy and consultations were done during the summer, delays were anticipated in receiving feedback. For a specific clarification regarding the CSS program which is coordinated by the YMCA of Greater Toronto, I contacted via e-mail Nicoleta Monoreanu, National Programs Manager for the YMCA of Greater Toronto. She gave me permission to quote her response in my paper.

\section{Target audience and dissemination}

Dissemination is central to successful Knowledge Translation. The stakeholder audience of the position paper is IRCC settlement policy-makers. Prior to dissemination, the position paper will be presented to the Ontario Council of Agencies Serving Immigrants to ask for their

support. Dissemination to IRCC policy-makers is intended to advocate for changes in settlement program structures and outcome measurement to include a family approach. Access to these stakeholders will be achieved with the help of Ms. DiZio who is a representative on the National Settlement Council. She will be instrumental in communicating with IRCC policy-makers for dissemination of the paper. The position paper includes two-page summaries in an English and French version (see Appendix 2 and 3) to optimize uptake by the audience as per previous KT practice (Shields \& Evans, 2012). Settlement-sector specific language was used to make this paper accessible to the audience. The paper was reviewed by the partners. The following chapter consists of the integral position paper, of which I am the sole author. 


\section{Chapter 3: Practical Position Paper}

\section{Preamble}

This paper is the result of a partnership with representatives from two influential settlement agencies in the Toronto region: COSTI Immigrant Services and WoodGreen Community Services. Their partnership was initially secured through the Integration Trajectories of Immigrant Families (ITIF) project spearheaded by the Ryerson Center for Immigration Studies. The ITIF project is an academic-community partnership funded by the Social Sciences and Humanities Research Council through a Partnership Development Grant.

The ITIF project began in the fall of 2014 and involves multiple researchers. It contributes to the existing body of research on immigrant families by exploring their trajectories over time and the role of families/social networks in immigration and settlement decisions. The entire ITIF research team was involved in the collection of the qualitative data, and each researcher analyzed the data with a particular research focus. They conducted qualitative interviews with 23 immigrant families who immigrated to Canada between 5 to10 years ago. All participating families had immigrated to Canada through the Economic Class, resided in the Greater Toronto Area, and spoke English. The participants were recruited with the help of the settlement partners, who also significantly contributed to different aspects of the project. The research findings will be published in a forthcoming edited volume entitled Migration is a Family Affair (Bauder). I am greatly indebted to the ITIF project team who has made the secondary data available to me for the purposes of this paper. The ITIF findings I refer to herein are those of Dr. Mehrunisa Ali's team.

I had the privilege of being involved on the ITIF project as a graduate research assistant for Dr. Mehrunisa Ali starting in January 2017. With the guidance of my supervisor, Harald 
Bauder, I decided to draw on the ITIF project for my master's research project. The development of my project idea evolved through ongoing communication with the representatives from the partner settlement agencies COSTI and Woodgreen since February 2017.

This project uses Knowledge Translation (KT) to transfer the research findings of the ITIF project into practical recommendations for government policy-makers to improve settlement services for newcomer families in Canada. Briefly, Knowledge Translation (KT) consists of converting knowledge into an accessible, relevant and practical format to ensure that it successfully 'transfers' to another stakeholder. Too often, academic research findings are published in discipline-specific language to a limited academic audience. The compelling findings of the ITIF project and the investment of community partners presented a unique opportunity to bridge the gap between theory and practice.

Consultations with settlement partners were held between March and July 2017 through a collaborative back-and-forth process to translate ITIF project findings combined with communitylevel observations into practical service recommendations. This position paper represents the combined voice of academic researchers and senior settlement practitioners; thus, I use the pronoun 'we' throughout. Its unique contribution is that it is action-oriented and evidence-based; formatted specifically for policy-makers and informed directly from evidence and practice. It is our hope that this paper can lead to improvements in settlement service delivery policy to better address the needs of newcomer families.

In this paper, I use key citations taken from the ITIF project interview transcripts as well as visual representations to illustrate findings and bring newcomer voices to the forefront. Unless otherwise indicated, citations refer to the ITIF project interviews. 


\title{
A Case for Families
}

\begin{abstract}
"Settling in a new country can be difficult and frustrating. It can be especially difficult for newcomers who are alone and do not have the support of their immediate family. In every society, the family forms the nucleus for social, physical, psychological and spiritual wellbeing. A healthy family is both a barometer of and a mechanism to promote the well-being of society." (Toronto Public Health, 2014, p.1)
\end{abstract}

Immigrant families plan their immigration trajectories and destinations long before they set foot in Canada. Families change and become reconfigured through the immigration and settlement process. It is a life-changing event that results in important sacrifices, changes in gender and family dynamics, living arrangements, and expectations of support. Having the support of a family network is the most important predictor of settlement success (Creese et al., 2008; LewisWatts, 2006; Telegdi, 2006).

Immigration, Refugees and Citizenship Canada (IRCC hereafter) plays a pivotal role in structuring the newcomer family through immigration policy, and shapes settlement through funding services and programs. IRCC holds the authority to enter into service agreements with organizations and represents the most important source of funding for newcomer settlement services across Canada (except Quebec). Settlement policies and program guidelines determine to whom and how services are delivered. Therefore, they have great influence on newcomer settlement outcomes.

On its Settlement Priorities webpage, IRCC (2017a) identifies as a key priority "improving knowledge creation and management through policy-relevant research and knowledge mobilization that $[\ldots]$ suggest concrete options for improved settlement service delivery". Recent 
academic research as well as findings from the ITIF project demonstrate that immigration and settlement, in a fundamental way, are family experiences. It follows that if the settlement sector is mandated to serve immigrants' needs, they must use a service framework that situates immigrants within these social realities.

This paper is designed to inform decision-makers about research findings on newcomer families that confirm the observations of settlement workers and can guide policy. Five key practical recommendations for implementing a Family Approach in the settlement service framework and policies are being presented to IRCC settlement policy-makers. This paper challenges the current individualistic structure of IRCC settlement program design and policy. Ultimately, we seek to improve settlement services for newcomers by influencing multiple levels of the settlement sector to reflect the interconnectedness of newcomer needs with a web of social relations.

\section{The Role of Family in Immigration and Settlement}

A review of the academic literature demonstrates there is a strong consensus "that the family, rather than the individual, is the integral unit of analysis within the immigration experience" (Cottrell \& VanderPlaat, 2011, p.268). Research shows that the experiences and needs of newcomers cannot be divorced from the web of interconnections they share with family and social networks. This section reviews the impact of immigration policy on the family as well as research on the settlement experiences of newcomer families. Findings from the ITIF project are presented. 


\section{Immigration Policy Impacts on Family Structure}

The 2016 Annual Report to Parliament on Immigration affirms that "Through temporary and permanent resident immigration streams, Canada selects foreign nationals whose skills contribute to Canadian prosperity, as well their family members" (IRCC, 2016, p.3). Immigrants who have been selected to become permanent residents of Canada, also known as Principal Applicants, can extend admission to their 'dependents'. Recognized 'dependents' are their spouse/common-law partner/conjugal partner and their unmarried children below 19 years old (IRPR, SOR/2015). This definition privileges the nuclear family model and prevents alternative family arrangements, such as extended family models. Thus, the support formerly afforded by extended family and social networks in the country of origin is significantly reduced upon immigration to Canada (Guruge et al., 2010; Hynie et al., 2011; Strasser et al., 2009). Satzewich (1993) observes that "the state [...] plays a fundamental role not only in selecting certain groups of immigrants but also in constituting certain forms of familial relationships" (p.316). This restructuring of the family shapes the settlement decisions and experiences of newcomers.

Family reunification in Canada is often mentioned by newcomers as a long-term goal (Phan et al., 2015). One Indian family who immigrated to Canada before the restrictions on family reunification ${ }^{4}$ explained that throughout immigration they "all stayed together just like a network, like support mechanisms and everything, housing, food, set up a job, and those kinds of things. We always move together" (Creese et al., 2002, p.6). Bergeron and Potter (2006) found that family class immigrants may have the most facilitated settlement process since they necessarily have at least one family member in Canada on arrival.

\footnotetext{
${ }^{4}$ see DeShaw (2006) for a historical overview of family reunification policy in Canada
} 
However, current quotas on the number of family class admissions maintain this category at a historic low, representing only $24.1 \%$ of annual immigration in 2015 (IRCC, 2016). Processing delays in applications for family reunification result in separation of family members for months, often years (Bernhard et al., 2005). Furthermore, eligibility for family reunification is now limited to spouses, common-law or conjugal partners, parents and grandparents, unmarried children below the age of 19 and related orphaned dependent children below the age of 18 (IRPA S.C. 2001; IRPR, SOR/2002). Other familial ties, such as adult or married children, siblings, cousins or other relationships are neither eligible as accompanying 'dependants' of immigrants, nor for family reunification in Canada. Unless selected as immigrants to Canada on their own merit, they will be separated. Plainly, immigrants who come to Canada with family, can only do so as a nuclear unit.

\section{Academic Research on the Settlement of Families}

"A great deal of what has been traditionally thought of as individual migration should be more appropriately conceived of as family migration" (Cooke, 2008, p.255). Research consistently shows that migration decisions are made at the family/group level and that the geographical landscape of social networks determine when and where individuals migrate (Boyd, 1989; Cooke, 2008). As many as $87 \%$ of immigrants report having friends, relatives or both living in Canada at the time of their arrival (Statistics Canada, 2005, as referenced in Wayland et al., 2006, p.86). Having family/relatives in Canada is the most important predictor of immigrant success and integration (Creese et al., 2008; Lewis-Watts, 2006; Telegdi, 2006). Bergeron and Potter (2006) conducted a quantitative analysis of the Longitudinal Survey of Immigrants to Canada (LSIC) which demonstrated that immigrants draw on their social capital (i.e. their connections in Canada) during their initial settlement period. Throughout the process, the presence of family facilitates access to settlement necessities (housing, employment, health) (Bergeron \& Potter, 2006) and 
provides stability for the pursuit of long-term goals (Creese, et al. 2008). Kustec (2006) made a unique attempt to reorganize immigration admission data into family units. He found that between 1990 and 2004, 50\% of immigrants entered Canada with one or more accompanying family members, while a majority of those immigrating alone were themselves family class immigrants admitted through family reunification.

According to the family investment hypothesis, in the process of settlement, members of families negotiate their roles (gender, labor, etc.), sometimes by making important sacrifices, in order to 'invest' in the success potential of another family member (Phan et al., 2015). As explained in the previous section, immigrants' social support networks from their country of origin, including extended family, are disrupted by immigration. When families are reduced to the nuclear core, sacrifices become absorbed between partners rather than shared among a larger group (Creese et al., 2008). For example, in a qualitative study with families from the economic class, researchers found that while male and female spouses may have similar education levels and labor market achievements in the country of origin, it is likely that the female spouse may sacrifice her first Canadian work experience (altogether or in terms of expected wage/skill) to support the career aspirations or re-skilling of her spouse (Phan et al., 2015). The families explain that the availability of extended family in their home country had facilitated the dual-career aspirations of the couple.

Immigration carries a number of other stressors that impact the family during settlement. Parenting roles are altered through the process of settling in a new country. Interviews with immigrant families reveal that parent-teen conflicts arise as a result of 'parenting across cultures', the identity struggles of family members, the greater English proficiency of teens compared with their parents, differing societal expectations of gender roles, and conflicting conceptions of adulthood and independence (Cottrell \& VanderPlaat, 2011). Immigration affects all generations 
of the family, both in Canada and abroad, and continues to have implications for future generations (Falicov, 2007). In sum, "family transformations are an inevitable feature of migration" (Falicov, 2007, p.163).

Family networks, when available, provide multiple forms of support as well as a strong reciprocity and are consequential to overcoming settlement challenges (Bergeron \& Potter, 2006; Bragg \& Wong, 2016; Creese et al., 2008; Lewis-Watts, 2006). In cases where immigrants have weak or no existing support network in Canada, they are compelled to form new social connections. Acquiring a social network is itself a coping strategy and an 'indicator of settlement' (George, 2002). Immigrants' social networks are as important to the integration process as their level of education or work experience (Lewis-Watts, 2006). However, research shows that the social networks of immigrants in Canada are smaller than those of their native-born counterparts, suggesting that expanding a social network is harder as a newcomer (Kazemipur, 2006). Family reunification with parents or grandparents can be a valuable strategy to acquire social support and improve settlement outcomes. Contrary to the notion that sponsored family members are burdens on society, family reunification was found to be mutually beneficial to both the integration of the sponsor and the sponsored, and to society (Bragg \& Wong, 2016; Creese et al., 2008; Lewis-Watts 2006; Vanderplaat et al., 2012). A number of scholars call for further research to uncover the significance and the functions of families and social networks to newcomer settlement (see Wayland et al., 2006).

Accordingly, immigration, on a very profound level, is a family experience (Cottrell \& VanderPlaat, 2011). Families undergo important changes and adaptations during immigration and settlement, namely living arrangements, family dynamics, roles, identity, relationships, expectations, and support (Cottrell \& VanderPlaat, 2011). It is only once we turn our attention to 
the family that we can begin to situate the needs of immigrants. Thus, using a Family Approach in immigration research and services is necessary to address the needs of immigrants. Findings from the ITIF project support existing research and add important dimensions to this knowledge base.

\section{ITIF Project Findings}

Qualitative interviews with immigrant families from the economic class reveal important findings that have implications for all levels of policy, not the least for settlement policy. Key findings selected for their bearing on this Knowledge Translation project are described below. They will be published in the forthcoming chapter Families' Roles in Immigration and Settlement, co-authored by Dr. Mehrunisa Ali, Marc Valade, and myself.

Definition of Family: Participants were asked to draw a socio-gram ${ }^{5}$ of who they consider to be their 'family'. Participants were familiar with the normative nuclear family model in Canada and consistently asked the researcher to clarify whether they meant 'just' the nuclear family or 'the whole family'. They were told to include all those whom they think of as family, regardless of predetermined models. Overwhelmingly, in addition to spouses and children, participants included parents, siblings, specific extended family members like an uncle, an in-law or distant relatives that played a role in their lives, as well as personal or family friends, in their representations of family. One child explained "That is why I put [Friend 1] in there [on the socio-gram], because he was the person that got me connected with the other people" (Participant \#11, Child 2). Furthermore, family members spread over different countries and continents. One participant included his uncle and his nephew on his socio-gram and noted that in the country of origin they had lived together in a joint family compound. Another participant's socio-gram included a family

\footnotetext{
${ }^{5}$ Socio-grams are a visual representation of one's own social/family support networks. The self is placed at the center and family members are connected by tracing a line outward and writing their name.
} 
who became their close friends in Canada. She explained that she considered the wife as her own elder sister because she was by her side during her C-section. Some participants explained that their definition of family had changed as a result of immigration. This participant's response portrays the experience:

"Actually, in my mind, the family means nuclear and living in one house. That is the family. But as an immigrant, I think of my friends, because they every time they support for me, like or emotionally and physically. It is not belong to my family but my feeling is like a family. You know in [country], we call to the someone, mother or father's friend who is very close, we call aunt or kind of relative... that is why I just put on my friends as a family. Also the other reason, I do not have any relative or family member in Canada. I have only my son and my husband...So I feel very isolated in Canada. So my friends are like my relatives. " (Participant \#8)

Therefore, important new relationships formed in Canada were included as part of the family.

Transnational Support: Thanks to communications technology, transnational social relationships could easily be maintained. Participants revealed that they relied on the emotional support of family members abroad, especially parents, and maintained frequent communication. Transnational family ties offered many different types of support: social, emotional, physical and financial. One participant revealed that his brother-in-law loaned him a large sum of money to ease his settlement. He said "although I did not use it at all because I was having enough with me. But it gave me peace of mind and a confidence" (Participant \#3). Emotional support was most prevalent: "my father he always support me in the sense like you have to be strong. In that sense, I mean emotional encouragement" (Participant \#4). These supports significantly facilitated the settlement outcomes of immigrant families, especially in the early years.

However, the extent of the support was diminished with time and limited by the disjuncture of living contexts. One participant put it this way: "Now I can feel the distance is more clear, 
emotional distance. Even with regard to my parents...I love them, they love me...but separation you know. Like you start building different lives and so family gets distant. Me, that is my experience" (Participant \#4). Several participants expressed that they missed their parents a lot and wished visits were facilitated by immigration policy: "it would be easier for my family, and everyone would be happier if she [mother] could come anytime she wants. Or if it was easier for my sister or anyone else to just come and visit" [...] "the government should facilitate families that are already here to bring family as visitors. Does not mean that they are all going to stay" (Participant \#19).

Some newcomers did not disclose some emotions or events to their families abroad to avoid having them be worried or sad. Feelings of being strongly connected were still present, but in some cases, maintaining contact was energy and time-consuming and it became difficult to keep up in parallel with the fast-paced life in Canada and balancing many responsibilities, "Because right now I do not have enough time to talk to everyone. Only I am giving importance to my parents, my husband's family and also my siblings “(Participant \#18). A number of participants sent gifts and money to their family members abroad as a way to reciprocate support.

Decision to Migrate: One participant summed up the common themes in immigrant families' decision to migrate: "the principal reason was one, having them [children] exposed to a first world education and two, having them in an environment which we considered safe and conducive to rearing a healthy happy family" (Participant \#17). The decision to migrate was made over a lengthy period and through ongoing communication with relatives or friends who were already in Canada (a sister/brother, an aunt, a former classmate, a former colleague, a friend, a friend of a friend). Social connections in Canada provided important information on how to prepare for immigration. 
The awareness that they would have established social connections when arriving in Canada provided confidence and security to families in their decision to migrate: "I think the most important is that they provide you with some type of security, like you know you can trust this person, you will not feel lost" (Participant \#6). As another participant put it "I felt comfortable. The fact that...I know the family; it is not strangers" (Participant \#12). Once they arrived in Canada, these social ties provided invaluable support, especially in the initial steps of settlement. They came to pick up the newcomer family at the airport, and housed them anywhere from 1 week to 6 months until they could get on their feet and rent their own apartments. They constituted important resources for information on where to go for things such as medical cards and social insurance numbers, orientation (transportation, weather, Canadian culture), ethnic food, and often referred them to settlement organizations. They offered advice about parenting, integration, or a first job and were called upon during an emergency. As the families progressed in their settlement process, the relational support between the newcomer families and their existing social network in Canada became more reciprocal and they were proud to say they could offer support in return "after one year, so, we were in the position to guide others for the same matters" (Participant \#16). Many of the participants explained that they are now themselves helping someone they know from their country of origin who is planning to immigrate to Canada: "We keep getting calls" (Participant \#11). Support had a multiplication effect: as families acquired supports and gained stronger stability and positions in Canada, they could in turn support other newcomers: "immigrant people...they help another immigrant because they can understand" (Participant \#13).

Social Networks: All participants agreed that their social networks were significantly reduced and disrupted through immigration. Most participants said that their social networks in Canada were far smaller than those they had had in their countries of origin. One participant explained that her 
social network and family had been very close in the country of origin because her family had lived in the same community for generations. Participants felt strongly the burden resulting from the loss of precious support, especially in terms of childcare.

"I was pregnant, I also need to take my older one, now that time she was only 20 months... and in my back home, my in-laws helped me take care of my daughter, so I just go to work, come home and play with my kids, that is it! But here [becomes very passionate and raises voice], I have to take care of everything by myself [very emotional]." (Participant \#5)

One participant longed for family reunification: "I realize that I needed my extended family. I think I would benefit from having my sister or my brother around over here" (Participant \#19). They explained that coming to Canada as a nuclear family and being separated from extended family members brought the immediate family (spouses and children) closer because they relied heavily on each other for support "We [spouses] realized we needed each other more than we would have necessarily at home. Because we had such a wide network and more supports" (Participant \#17). In the words of another respondent:

"So we went through the hardships together, then after...going through the hardships I feel my family more united, closer. Because you know we start from zero when I came here, nothing here, no contact here, just my husband here, me and my girls. So I feel as though we went through some very difficult things in our marriage, right now, we are all working very hard, and are much more closer." (Participant \#5)

Many participants had no existing family members in Canada when they immigrated. With time, new social connections were formed with colleagues, neighbours, other parents, a settlement worker, classmates, neighbours, colleagues and bosses, co-volunteers, faith community members, newcomer program participants, sports club members, library folks, and even a stranger encountered on the street: "Family friends, like, we met them on our path.... She has sort of...adopted us I guess" (Participant \#11). Another participant said, "A lot of the people here are 
my friends but - I mean some are co-workers, some are friends, and some are like family now" (Participant \#12). Many immigrants turned to settlement agencies to expand their social networks.

Settlement Experience: Several families decided that only one of the spouses would travel to Canada before bringing the rest of the family. One participant said she wished her children did not have to see her suffer in the initial struggle to settle. This strategy allowed for one family member to prepare for the arrival of the others, even if it meant they were separated for a few months. The lone immigrant did as much as possible to ease the transition for the family. One mother painted her daughter's future room into 'a princess room' by painting the walls and furniture pink to make sure she would like their new home. Once in Canada, partners coordinated their occupations based on responsibilities and their financial situation. "One person he just study, and one person working, and then, one person is working, and maybe I am studying" (Participant \#2). Some women who had never worked in their lives took up jobs to support their husbands' studies. Likewise, husbands supported their spouses, "I am trying my best to help her to support her in...our day-to-day routine work, like helping her with...cooking or...doing laundry... even my son help us a lot in that case" (Participant \#14). Another participant stated:

He [husband] was willing to take care of the kids, learn the English, and give me the opportunity. He was supporting me in every step during my job evolution. He was the one who was training me for the interview for the managerial position, and telling me why I am supposed to be a manager versus thinking am I able to or not. (Participant \#11)

Settlement plans and decisions were inevitably tied to family circumstances. One participant was determined to learn English to ensure she could understand her children as they grew up in Canada. Each individual's personal settlement experience was greatly mitigated by the family. For example, when a single-mother's son encountered problems with the law, this had repercussions on her own emotional well-being and her conjugal relationship. In another case, a massive debt incurred by hospitalization of their child during the un-insured arrival period added enormous 
strain on the family. Family members supported each other in every way they could. One participant appreciated that his spouse was understanding of the decline in lifestyle and status they experienced after immigration, and for being less demanding during the period of high stress.

"Thank God, I am lucky in that aspect I got. She did not put a burden on me. Even she used to share [the burden]. She was always, you know, encouraging me and she understood like after a twelve-hour work, I am really tired. She did not do unnecessary demands and you know, sometimes, they say "Oh, please take care of us." During six months. No. Never. She was really, really supportive." (Participant \# 3)

In another case the wife and children made sure to stay quiet during the day to let their father, who worked night shifts, get some sleep. Regardless of whether immigration was of a single individual or a family, their experiences were very much described at the family level. In two cases, one parent returned to the country of origin to work and financially support the family in Canada, because of the lack of employment they experienced here. A participant (\#15) described her family's immigration trajectory as a "family explosion", because it resulted in their separation. When families struggled with settlement challenges, they reminded themselves that the primary goal of their decision to migrate was to provide a better future for their children.

Despite all this evidence for the need to pay attention to families, the current settlement framework does not incorporate the family sufficiently. Findings represent the voices of immigrants who want to improve the services that concern them directly. Qualitative research provides policy-makers with access to the real testimonies of newcomer families. As Bernhard et al. (2005) write, "this attention to concrete family realities is the only way to appreciate the complexities of the situation" (p.3). For the settlement sector to be informed by a family approach, evidence from academia and practice must be bridged into policy and program design. 


\section{Current Service Framework in Settlement}

The current settlement framework treats immigrants as discrete individual units and overlooks the group-level. As a result, there is a gap between academic work demonstrating the importance of situating immigrants within families and settlement sector practice and funding. During the immigration application process, families are framed as one designated Principal Applicant accompanied by dependants. By the same token, the family is reduced to a single individual representative who is also assumed to be the provider of the family. The Principal Applicant is selected to become a permanent resident of Canada through an individualistic assessment of his/her 'human capital' (credentials) without recognizing the complex social resources that uphold that position and the responsibilities that accompany it (Creese et al., 2008). Put succinctly, "the current discourse surrounding family migration and the immigration of professionals $[\ldots]$ continue to assess and value the individual over the migrating family unit" (Phan et al., 2015, p.2076).

Furthermore, almost all statistics on immigrants and immigration available in Canada are at the individual level (Kustec, 2006). We know how many individual immigrants enter Canada every year, and annual immigration quotas are fixed in those terms, but little is recorded about the number and composition of families. Statistics on the integration outcomes of newcomers are also predominantly measured at the individual level, often solely in economic terms, like in the Longitudinal Survey of Immigrants in Canada database (Vanderplaat et al., 2012). The multiple contributions of family members whose support sustains economic and social integration are disregarded.

Accordingly, government funding for settlement services is determined by a target number of unique individual clients. Assessments of these programs are also tabulated by the number of 
individual visits. The over-arching framework of IRCC-funded settlement programs is individualized. The Social Planning Council of Ottawa has argued that "Integration services should be provided within the context of the family and not just to individuals as separate entities. This holistic approach will strengthen the family unit" (Social Planning Council of Ottawa, 2010, p.24). In the following section, the settlement priorities and policies of IRCC will be reviewed, as well as the contract agreements that delineate services.

\section{IRCC Priorities and Settlement Policy}

In the Settlement Programs Terms and Conditions, CIC (now IRCC) is clear that "for Canada to realize the economic, social and cultural benefits of immigration, newcomers must integrate successfully into Canadian society" (2016, p.2). As such, IRCC Settlement Programs are fundamental in helping immigrants and refugees "overcome barriers specific to the newcomer experience" to facilitate their participation in all spheres of life in Canada (IRCC, 2017b). The focus of these programs is to provide newcomers with information and referrals, language training, support with employment, and community integration. Programming is delivered by Service Provider Organizations, principally settlement organizations.

Services are delivered directly to an eligible newcomer client "in order to advance their individual settlement outcomes" (IRCC, 2017a). Since the modernization of the service framework in 2008, settlement programs funded by IRCC are now categorized into six core streams: Needs Assessment and Referral, Information and Orientation, Language Training and Skills Development, Labour Market Participation, Community-Connections, and Support Services. Within each of these streams, there are specific branches of services for newcomer populations 
with unique needs, such as women, youth, children, seniors, and refugees. Gender-specific needs and the prevention of family violence are noted as a priority area (IRCC, 2016).

In the 2017 funding call, IRCC also declares that it is committed to "foster new (or strengthen existing) skills and credentials which directly contribute to better operations, services and settlement outcomes for newcomer clients", including "supporting the development of tools to optimize services offered by the settlement sector" (IRCC, 2017a). This priority direction reiterates an earlier commitment made to the Ontario Council of Agencies Serving Immigrants (OCASI) in 2010 whereby CIC (now IRCC) indicated a positive stance to working with immigrant serving organizations "to build a client-centered approach" for program design and service delivery (OCASI, 2010, p.4). Programs offered to newcomers by organizations are determined by service agreements.

\section{Settlement Organization Service Agreements}

IRCC "manages and delivers settlement services though contribution agreements with service provider organizations across Canada [except Quebec]" (Standing Committee on Citizenship and Immigration, 2010, p.2). IRCC contribution agreements represent the most important source of funding for newcomer settlement services (as much as 80-90\% of total funding for some providers). Service provider organizations are diverse in their size, clientele and types of programs offered. They range from small ethno-specific community hubs, to multi-location and multi-ethnic agencies. Service provider organizations can apply to IRCC for funding based on one or more of the six program focus areas outlined above (CIC, 2016).

The most widespread service offered by IRCC-funded settlement organizations is the Needs Assessment and Referral program, which is designed to identify the clients' needs and refer 
them to the appropriate services to address those needs. The settlement worker can develop a personalized settlement plan and reassess the client in the future, but there is no follow-up strategy (except for government-assisted refugees). The Information and Orientation program is often done in group workshops, where newcomers are provided with information to facilitate their integration and orient them in their communities. The different Support Services available to help newcomers access services includes crisis counseling (CIC, 2016). Finally, the Community-Connections program is intended to help newcomers connect with fellow community members to develop friendships, contacts or professional networks, including mentorship pairing (IRCC, 2017c).

As indicated in their contributions agreements, service providers must report back to IRCC on their results. Depending on the program, reporting can take the form of submission claims for costs, progress reports, or annual reports with statistical data and narrative remarks on meeting the Settlement Program objectives and outcomes (CIC, 2016). Statistical reporting requirements are typically a form of performance measurement data collection that service providers are responsible for, such as number of clients serviced, demographic information (tombstone data) on clients, and number of referrals (CIC, 2011). Reporting data is also collected on an instant basis, transmitted to IRCC via an electronic system called the Immigration Contribution Agreement Reporting Environment (iCARE) and is used by all IRCC-funded service provider organizations to report on services delivered to newcomers (CIC, 2016). The data collected through these reporting methods is used by IRCC to evaluate the program and determine funding renewal (CIC, 2011).

\section{Towards Evidence-based Settlement Policy}

While service provider organizations are under multiple accountability expectations, there are few provisions for IRCC to remain accountable and receptive to service-level insight. This is 
not to say IRCC has refrained from making improvements to programs and services. It is recognized that IRCC has made significant strides over the years, the most recent example being the Gender Based Approach (GBA+) which was incorporated at all levels of immigration and settlement policy (IRCC, 2016). It certainly constitutes one such advancement and it deserves to be applauded. Nevertheless, settlement organizations' negotiating power or channel of influence to make changes to settlement programs based on their front-line observations and expertise is limited. Recognizing that "as service deliverer [...] [they] are in a strategic location to assess the effectiveness of policy and programming from a frontline deliverer/community practitioner vantage point", they constitute indispensable 'knowledge brokers' (Shieds \& Evans, 2012, p. 262). Their observations about incorporating the family in settlement programming strengthen academic research findings. Fortunately, the current government has been vocal about its profound commitment to evidence-based policy-making and programming.

According to the IRCC Settlement Priorities webpage for the 2017 funding call, the production of knowledge by Immigrant Serving Agencies (ISA) through research is a key strategy to generate evidence-informed policy and settlement practices (IRCC, 2017a). Specifically, IRCC calls for project proposals inspired by a Knowledge Translation approach where research on the settlement experiences of immigrants can lead to improved settlement service delivery. IRCC writes that such a project should aim to "deliver results in the area of knowledge translation and mobilization to help the settlement sector and practitioners benefit from relevant research and knowledge products" (IRCC, 2017a). This position paper is an attempt to inform a client-centered approach using the input of different stakeholders and to present recommendations. Through sustained consultations, knowledge was adapted for the purposes of settlement practice and related policy. 


\section{Proposing a 'Family Approach' in Settlement}

In order to offer client-centered settlement services that address the needs of immigrants as members of families, and for those services to be funded accordingly, settlement practitioners and academic researchers agree that the family lens must be officially recognized and imbedded in these structures.

\section{Observations from Practice}

Based on consultations with partner settlement organizations (COSTI and WoodGreen), settlement workers confirm that the emotional support afforded by family is necessary to cope with the challenges of settlement. Enhancing the capacity of family support has potential to be empowering. Clients make it clear that they see themselves as members of families whose settlement decisions are heavily interconnected with their family/social networks, and therefore demand a family approach in counselling and services. Newcomers do better when they have a wider social network. As observed by the Social Planning Council of Ottawa (2010), social networks provide access to different types of support and information, an asset for settlement, which settlement organizations are in an ideal position to facilitate.

As demonstrated by the ITIF project findings, immigrant families always involve to some degree a transnational dimension. Settlement workers are often confronted with the needs of clients who are dealing with immediate family separation (spouse and children). Transnational family separation requires important adjustments and is a chief dimension of settlement (Toronto Public Health, 2011). Settlement practitioners welcome the government's progress in reducing the processing times for family reunification of spouses and for making it a priority (IRCC, 2016). That, however, does not compensate for the lack of services for families who are undergoing these 
difficult and emotional transitions that threaten family cohesion (Social Planning Council of Ottawa, 2010).

Upon taking a closer look at settlement services, it becomes apparent that there is little social support for care work, non-economic activities or emotional well-being (Zhu, 2016). This is symptomatic of a general trend in settlement programs where the provision of emotional or social support is not appreciated on equal footing with information, employment or language services. It is difficult for newcomer families to open up about challenges of a relational and emotional nature. The emotional challenges experienced by newcomers throughout the settlement process are 'common', as stated on IRCC's webpage (IRCC, 2017c), and, as such, should be an important consideration of settlement programming.

Generally, there is a lack of an integrated family approach in services and programs. Programs address children, youth, parents and seniors separately. The family is not formally recognized nor reflected by federal program structures and statistics. There is no agreed-upon framework to achieve this. The current systematic individualized structure fails to situate immigrants as members of families. By the same token, it overlooks the roles of different family members in facilitating/supporting, mitigating or hindering the integration process and program outcomes of individuals. This gap between academic research and settlement services must be addressed.

Defining 'Family Approach'

The Ontario Council for Agencies Serving Immigrants writes: "As immigration becomes the source of population and workforce growth, the objectives and structure of the immigration program will have significant and long-term impacts on the cohesion and strength of Canadian 
society" (OCASI, 2011, p.2). Serving immigrants as members of families is imperative to properly address their needs, "families are important because when they came here, they can support each other. They know each other. They are not one individual” (Participant \#21). Consultations with settlement organizations confirm there is a need to incorporate a social networks/family approach in client services.

Incorporating a Family Approach implies a re-thinking of the framework behind programs and services, policy, settlement funding, outcome measurement, and service delivery, which are currently using an individualistic approach. This structure functions as a whole and it would seem futile to address only a single strand. We propose three over-arching orientations for action:

- Need to complicate the current conceptualization of immigrants as individuals

- Need to incorporate holistic family approach in settlement policy, program design, service delivery, data collection and funding

- Need to draw on empirical evidence that recognizes and lends support to settlement workers' first-hand observations and experience-driven insight

Looking at the family as a unit offers valuable insight and a more authentic representation of immigrant settlement experiences. This includes children, youth, parents/partners, extended family and close friends. While each family member has personal settlement experiences, most newcomers assess their settlement at the family level. A good example is Brouwer's observation that "the newcomer community does not consider anyone settled until their family is [in Canada]" (Brouwer, 2004, p.14, as cited in Bernhard et al., 2005). Speaking of her partner, one participant put it this way: "We have family, we have two young kids, we live together. So we went through all the hardship, all the happiness and all the sorrows together" (Participant \#5). Another participant highlighted the role of her children in the families' settlement: 
"I know you are working and carrying as much load as I am [to CHILD2]. You are working and carrying as much load [to CHILD3]. She is working [referring to CHILD4] and carrying. We are all working... Not only that...You adjust your school schedule time-table to be able to pick up your sister. Drop her on games...Like, we are all sort of working together." [...] "It is not about age, it is about how much we can rely on each other in building the family." (Participant \#11)

Two participants highlighted the impact of the circumstances of parents on children:

"Because when they will see their parents crying every day, struggling every day, going not well dressed. Not food, always tense..." (Participant \#13)

"Unless the policies support those immigrant families, unless the immigrant families, especially the children, do not experience the prosperous mom, they will not have any role model... The mom might stay at home or might take some general job...the dad might drive a cab and the children or the family in general might not get the quality time to spend with their family member to teach them and to show them the way forward. I think that needs to be changed." (Participant \#23)

Immigrant families have important problem-solving capacities and empowerment potential upon arrival. They are usually well prepared and highly motivated for success upon arrival in Canada. They are also incredibly resilient and ready to make some adjustments. Yet, they collectively face a number of social barriers that hinder their settlement on many levels. The purpose of this paper is not to tackle the barriers per se, but to recommend changes to the settlement framework and methodology to ensure the needs of newcomer families are being identified and addressed and that the support capacity of families is enhanced through programs, which can significantly empower them (capacity-building). With the help of the partners, we propose five practical recommendations on how services can be modified to incorporate a Family Approach while still being consistent with program objectives.

\section{Practical Recommendations for Settlement}

The purpose of the recommendations is to empower immigrant families to acquire social supports for settlement and to provide both settlement organizations and IRCC with a family-level 
representation of newcomer settlement needs for future evidence-based policy-making. This approach is more holistic and prevents escalation of family needs into crisis intervention. The five practical recommendations are the following:

1. Inscribe the Family Approach as an explicit framework/method of the Needs Assessment and Referral program and the Information and Orientation program service agreements

2. Add a section on the family in the Needs Assessment and Referral iCARE reporting platform, with markers to identify family needs

3. Coordinate settlement needs at the family level by linking family members' files in iCARE to reflect the inter-connectedness of needs and collect social capital measures

4. Enhance the recognition of family needs through the expansion of para-counselling support services, inclusive family programs, and social networking programs

5. Adopt an inclusive and flexible definition of family across settlement policy

\section{A Family Approach Program Framework}

According to IRCC (2017a), "when multiple and intersecting needs are identified, the needs assessment process should result in the development of personalized settlement plans to refer and guide newcomers along their settlement pathway". Yet, the program structure overlooks the fact that the 'multiple and intersecting needs' of individuals are interconnected with family/social networks who provide support or lack thereof, and mitigate the individual's settlement decisions. Needs assessment of newcomers by settlement workers lack a consistent framework to situate needs and resources of immigrants within social networks and families. At present, the application of family considerations is inconsistent across settlement practice: some settlement workers are attuned to family needs and some are not. Using a Family Approach will allow settlement practitioners to better identify and conceptualize settlement needs. Therefore, we recommend that it be explicitly stated in the service agreement and the program description of the 
Needs Assessment and Referral program and the Information and Orientation program. This implies that family considerations will be taken at all steps of the program. The framework will endorse settlement workers' efforts to include the family in their service delivery as part of funded work.

Recommendation 1: Inscribe the Family Approach as an explicit framework/method of the Needs Assessment and Referral program and the Information and Orientation program service agreements

\section{Identification of Family-Related Needs}

Toronto Public Health used to have funding for a program called Reunification and Adaptation Program, specifically for clients who faced challenges related to family separation or reunification with family members. In their report, they note that resources and services to identify issues relating to family reunification/separation are under-developed (Toronto Public Health, 2011). Bernhard (2005) and Zhu (2016) draw our attention to the needs of working mothers, for example, whose needs for social support are rarely identified. Families in which both parents are working, families in which parents are studying to update their credentials, versus families that are dispersed transnationally and families who are investing in starting a new business have considerably different needs.

At present, there are some programs directed specifically to parents and families, such as the Parenting and Family Supportive Counseling (Toronto), Parent Support Program (Toronto), Newcomer's Centre for Child and Family (Vancouver), Multicultural Early Childhood Development (Vancouver), Cross-cultural Parenting Program (Calgary), Support for Expectant Parents and Families with Babies and/or Toddlers (Calgary), and Ten-week Multicultural Family 
Program (Edmonton) (Zhu, 2016). However, because family matters are neither addressed as part of the Needs Assessment and Referral, nor in the Information and Orientation, they are not flagged in the early phase of settlement. This lack of a preventive approach results in one of three scenarios: 1) the settlement worker goes beyond current program guidelines by correctly identifying the clients' family-related needs and provides referrals (un-funded time and work); 2) the family is left to themselves to identify their need and find services; or 3) the issue escalates to 'family crisis' level, in which case they are referred to specialized programs for family violence or mental health. While many families find ways to overcome problems, the third outcome is not unlikely, which explains why family services funded by IRCC are consistently associated with partner and/or intergenerational violence, serious conflict, abuse or mental health problems. The Social Planning Council of Ottawa notes that "there are valuable services in different languages offered to victims of gender-based violence in Canada, but a preventive approach is missing" (2010, p.18). The needs assessment is the ideal time to identify family needs and refer clients to appropriate services.

\section{Preventive identification of needs and referral}

To compensate for the absence of indicators of family needs in the iCARE Needs Assessment and Referral platform, settlement organizations have developed their own tools to ensure their settlement workers are attuned to family needs that are currently being overlooked. COSTI uses an internal client assessment form to collect data like children's wellbeing, bereavement or losses, support networks available/isolation, community involvement, family dynamics, separation, reunification, pregnancy, family law, senior services etc., and requires the settlement worker to write case notes, identifying which needs require attention in the short versus long term. Another point of comparison is the IRCC-funded Client Support Services (CSS) program offered for government-assisted refugees which uses a much more integrated and family- 
focused assessment. Two key measure from the assessment that should be asked to all newcomers are: "Do you have support when needed from family or friends?" and "Do you know someone in Canada you can talk to for personal matters?" This is a key measure of emotional support available to the newcomer.

"Whether you are coming into a readymade family which is you become a part of - or you are taking your own family with you. That, the need for family is very important... the family is extremely important for that support" (Participant \#17). An important way to operationalize the family-approach is to devote a section of the Needs Assessment in iCARE to family needs. Based on evidence and comparative practice, we suggest three indicators that could be added to the needs assessment:

- Family reunification and separation (dispersed family, communication, attachment difficulties, recent reunification, role changes, financial, paperwork)

- Family support (emotional support, family activities, couples' communication)

- Community/social support (safe space, friends, mentor)

Capturing family and social support needs through the addition of these three simple measures would significantly prevent the escalation of family/social issues to crisis-level. Referrals to appropriate support services should accompany these fields of data collection.

\section{Family information and the promotion of help-seeking behavior}

The Information and Orientation program contains references to the family in the section on Canadian law and justice, but only as it relates to family violence/abuse and family law. It is our position that the Information and Orientation program would significantly benefit from a section devoted to family matters. We strongly encourage providing information on parental roles in Canadian society, authority and child-rearing, adolescence and age of majority, family activities 
and family life, supporting your spouse during settlement, childcare and school, pregnancy, family planning, retirement planning, transnational support strategies (use of technology, safe money transfers), and strategies for building social networks. Providing this information to newcomers empowers them to make self-assessments and encourages help-seeking behavior by providing them with knowledge on issues they may encounter.

\section{Data collection on the family and associated needs}

Settlement professionals and researchers alike denounce the lack of government data on families settling in Canada which limits the capacity to conduct informative quantitative research (Bernhard et al., 2005; Vanderplaat et al., 2012). More importantly, it restricts the capacity of IRCC to inform policy and programming decisions based on hard data. In the 2017 report by the Standing Committee on Citizenship and Immigration, recommendation \#32 urges IRCC "to counter the reliance on qualitative and anecdotal evidence" by establishing guidelines to track quantifiable data on family class immigration to inform decisions regarding this category (p.59). Recommendation \#36 adds the necessity to gather data on the diverse contributions of the family unit, both economic and non-economic.

IRCC is informed through iCARE of the referrals given to the client for logistical services (health, school, language, employment) and also for social services (social networking, community involvement). We contend that it would be beneficial for IRCC to collect data on the family in order to get a better understanding of family needs and dynamics of settlement as a family unit. In addition to the three proposed additional measures for family needs, demographic information (tombstone data) pertaining to the family is essential. We recommend collecting the following measures in iCARE: 
- Family composition (marital status, \# of dependents, age of dependents)

- Family configuration

- Family roles/responsibilities

To avoid losing important data, settlement organizations that have the capacity have developed their own database where they record complementary information and indicators that are currently being overlooked by the iCARE data collection. This implies that settlement workers must find time to enter client data into two separate databases (internal and iCARE). Instead, incorporating family data directly into iCARE would both provide IRCC with evidence on family settlement to inform decisions and would save service providers the loss of precious time.

Recommendation 2: Add a section on the family in the Needs Assessment and Referral iCARE reporting platform, with markers to identify family needs

\section{3. iCare Database and Family Unit Analysis}

Under the service agreement and the iCARE platform, settlement workers are required to create one individual profile per client they serve. There is no client file created for children/youth under the age of 18 because they are not considered 'unique clients' under the IRCC service agreement. Client files are created in iCARE using the Unique Client Identification (UCI) number on the newcomer's immigration document which links the settlement file to the immigration file of the client on IRCC's end.

Individual client profiles fail to reflect the inter-connected family needs. If a mother receives the Needs Assessment and Referral service to get help registering her child in school, or to be referred to a food bank because she cannot afford diapers and baby formula, a client file will be created only for the mother and not for the child. Furthermore, if a couple seek services together (for affordable family housing, or for a 'joint settlement plan'), a file will be created for each partner 
individually, without any indication in their files that they received services jointly or that their needs were connected. Although IRCC would technically have the capacity to link family member files by tracing the UCI numbers back to the family members on the immigration application, we are not aware that this is currently being done.

This individualized filing system has important policy implications. Fundamentally, policy-makers receive only individualized data and no data whatsoever on the family as a unit. This neglects an important level of analysis for settlement: the family unit. Findings from the ITIF project showed that many settlement measures are best captured in fluid and soft concepts/outputs like well-being, isolation, household dynamics, friendship/support network, transnational support, etc., because most needs are relational. The concept of 'integration' is hardly individual; it is relational to social surroundings.

We find it particularly useful to contrast the iCARE client filing approach with the Client Support Services (CSS) program. The CSS program is a national program designed to enhance the Refugee Assistance Program (RAP) and is geared to government-assisted refugees. Because resettled refugees have specific needs for care and support once they arrive in Canada, the CSS program uses a case management approach with home visits and pre-determined follow-up appointments over the first year of settlement. What is particularly interesting about the program approach is that the case management is done both at the individual and family unit level.

The CSS program is coordinated by the YMCA of the Greater Toronto which manage the centralized database on CSS files. The CSS database filing system works as follows:

"A family case consists of a Head Of Family (HOF), spouse (if applicable), and all children below the age of 18 . The links to all of their individual profiles can be found on the family's dashboard for easy access. Whenever you access any of the individual client's file, you can see a list of family members that are part of the same family. Children over the age of 18 are recorded as a separate file, since they are receiving their own needs assessments. The 
database allows for these members to be linked to their parents' family as well, since the database allows for any client to be a part of more than one family (for example, their own and their parents')." - Nicoleta Monoreanu, National Programs Manager, YMCA of Greater Toronto (Personal Communication, July 27, 2017)

The CSS program filing system serves as a good reference to suggest a similar template for iCARE, but without the case management aspect of the CSS program. This technique would provide settlement organizations and IRCC with a representation of family level needs, not only individual level. When needs that are relational are identified, a link to the 'family dashboard' or to the specific family member could be inputted.

Promoting a family approach in the Needs Assessment and Referral service does not necessarily entail referral for family counseling. Rather, it means addressing the needs of an individual in relation to a family (i.e. while recognizing that doing so has an impact on other family members' settlement as well). Suppose a client who is married requests assistance in finding employment, but confides that she is worried about the ramification of her working on her spouse who is himself struggling to find work and 'under a lot of stress'. In this circumstance, the settlement worker, understanding that the client is referring to stressors of gender role reversal and implications for family tension, strongly recommends to her client that her spouse make an appointment for referral to employment services as well. Seeking settlement services always remains voluntary, and we recognize that individual members have different needs, but they do not stand alone; their trajectories affect each other. It is possible to address the family without getting into 'family politics', so to speak. Settlement partners on this project have made it clear that settlement workers are doing this work already, albeit informally. It is our position that this type of relational information should be reflected in iCARE to match the reality of newcomers served. 
Recommendation 3: Coordinate settlement needs at the family level by linking family members' files in iCARE to reflect the inter-connectedness of needs and collect social capital measures

\section{Social Support Capacity-building}

Immigrants are deeply affected by the 'shrinking' of the family that results from immigration, the limited family reunification options, and the loss of social networks. In the words of one participant: "Born in [country x], grown up in [country x], of course lots of friends, family, lots of connections. Feel like [a] human being in [country x], but now no." (Participant \#9). Their social networks in Canada are smaller than those from their country of origin. This validates the idea that building a new social support network as an immigrant in Canada is difficult. It is especially concerning since the smaller the network the lower the likelihood of it offering different types of support (Bergeron \& Potter, 2006; Kazemipur, 2006). In the academic literature and the ITIF project findings, different types of supports were identified: informational, social, emotional, physical, financial. In a study by Simich et al. (2005), social support was found to benefit newcomers by "fostering a sense of empowerment, community and social integration, building networks, sharing experiences and problems, reducing stress, and contributing to physical and mental health" (p.263). The optimization, empowerment and capacity-building of newcomers' social support networks is guaranteed to yield positive results. Enhancing the social supports of newcomers deserves to be a stand-alone settlement objective with adequate programs.

\section{Social network facilitation}

Under the current structure of the Needs Assessment in iCARE, the settlement worker is required to assess the needs of the client based on different settlement objectives. One of the settlement objectives is to acquire knowledge of social networks, professional networks, 
community services or community involvement. According to consultations with settlement partners, clients who are identified to be in need of social networks, like seniors, are referred to senior groups or English conversation circles. Other settlement organizations said they referred clients to Language Instruction for Newcomers Clients courses, Information and Orientation workshops, which offer a secondary opportunity to make connections and socialize, even if networking is not a service agreement objective/outcome of these programs. Overall, settlement partners said they recognize that newcomers do better when they have a wider social network, but that programs dedicated to this objective were scarce.

The Community-Connections stream of the six Settlement Programs is an IRCC initiative as part of the modernized service framework to foster social networks. Community-Connections programs are community-specific and place-based (organization, schools, libraries). Their objective is to "foster active and meaningful connections between newcomers and host communities, and enable newcomers to develop a sense of belonging" (Burr, CIC, 2011, p.1). These include community activities, public institution outreach to communities, cross-cultural activities, mentoring and networking (CIC, 2016). One participant in the study referred to the program this way:

"This is a central discussion program. They have in some libraries... they offer discussion that the people gather from every - the immigrants...It makes their communication better and it makes their socialized...that is great. I think that is a good program but it is not very common. Not in every library" (Participant \#15)

In her report, an IRCC policy analyst writes that "while these programs give essential support, there is an appetite for broader engagement" (Burr, CIC, 2011, p.3). According to settlement partners, the Community-Connections programs they had encountered were predominantly geared towards professional mentorship. Nonetheless, they agreed that the Community-Connections program has potential to be significantly expanded because of its core values that align with a 
social network/community-building approach. We strongly urge IRCC to pursue the development and funding of Community-Connections programs, especially those targeting the development and enhancement of social support networks.

\section{Tackling unmet needs: emotional support/counseling}

"I think we should have newcomer focus groups, we have focus groups for people who may have a drinking problem, but why do not we have a focus group for newcomers who are having difficulty finding a job? ...And also to provide mental support for the people. Seriously, I would say the mental health of the newcomers is very important. Because if a person suffers from this, the whole family will suffer from this. So in the end it is going to be a problematic family." (Participant \#6)

Newcomers interviewed in the ITIF project turned to settlement agencies for instrumental, social and informational needs, but they also sought services to respond to emotional needs. IRCC accepts that emotions of despair, frustration and isolation are a natural part of settlement in a new country (IRCC, 2017c). However, services for emotional support are lacking in the sector: "lack of counselling or coaching, which is very much needed for any immigrants. Mental support [...] so they [immigrants] will not be broken down." (Participant \#13). In fact, consultations with settlement partners revealed that providing 'emotional support' to a client does not fall under the definition of advancing the settlement of newcomers. Rather than constituting a service on its own, emotional support is not accounted for and is positioned outside of 'progress' in IRCC settlement terms. In these instances, settlement workers are caught between the contradicting terms of their obligations and the needs of newcomers. Settlement workers for the most part steer away from the family matters of their clients unless there is domestic violence or serious inter-generational conflict, in which case they refer them to family crisis counseling, if culturally-sensitive services are even available at all. Waiting times for family counseling services are very long. The Report of the Standing Committee on Citizenship and Immigration on Best Practices in Settlement 
Services published in 2010 (after the modernization of the service framework), identifies needs that are unmet by settlement services. The Committee reports that family counseling is "not adequately covered by settlement funding" (p.7). They stress that if met, it would lead to increased well-being and better settlement prospects for immigrants. The positive impacts of counselling can have returns for many inter-connected newcomer families.

Clients can be reluctant to speak openly about family problems or emotional support needs because of the stigma associated with them. They usually come forward for help regarding family reunification paperwork or if they are experiencing abuse/crisis. Needs for emotional support and families are consistently associated with specialized services for domestic violence or family dysfunction/crisis (see IRCC, 2017a). In those instances, a case management approach is used where family counselling is provided, often in conjunction with mental health assessments. This approach pathologizes family needs, but most importantly, it addresses family needs when they have reached a level of crisis rather than preventing escalation. We argue that services providing emotional support could play a key role in prevention. It is essential that emotional support be offered through a recognized form of service on par with employment, housing or information needs. On the IRCC webpage, para-counseling is referred to as a Support Service available to newcomers. Settlement partners were not aware of funding for para-counseling as a Support Service offered in tandem with the Needs Assessment and Referral service. We strongly recommend the systematic deployment of para-counseling Support Service in service agreements with organizations who offer the Needs Assessment and Referral program. Finally, we appeal to IRCC to develop family support programs that are holistic and adapted to newcomer-specific realities. 
The 2017 Report of the Standing Committee on Citizenship and Immigration recommended that IRCC fund programs to support the unique needs of Canadian families who face delays and separation during the sponsorship of spouses and children. Toronto Public Health (2011) and scholars also call for programs such as support groups specific to family separation and reunification (Bernhard, 2005; Falicov, 2007). Children who endure separation/reunification are torn between emotions. One participant in the ITIF project, a 10-year-old who reunited with her mother after 10 months of separation, explained that she was very upset to leave her grandparents and uncle who she was living with, but relieved to see her mother at the airport. The Social Planning Council of Ottawa (2010) stresses that there is a pressing need for better support programs for immigrant parents/families that embrace 'inclusive family support models' and that are culturally competent.

For example, in a three-year pilot project, the Ontario Ministry of Citizenship and Immigration funded the Newcomer Youth Program. All newcomer youth were eligible for participation (not limited to 'crisis cases') and were recruited by settlement organizations. Their program approach involved sessions with the whole family as well as with the parents. They evaluated the outcomes of the program by measuring improvement in inter-generational relations, family dynamics, participation in family activities, and participation in volunteerism or community activities. The contract agreement specified that the expected project outcome was "newcomer youth have social and family connections that facilitate bonding (sense of belonging), cultural and intergenerational bridging and civic engagement". In the annual program report, organizations outlined the importance of connecting with parents in order to access the youth. 
Recommendation 4: Enhance the recognition of family needs through the expansion of para-counseling support services, inclusive family programs, and social networking programs

\section{Operational Definition of Family}

An important finding of the ITIF project is the changing and fluid definition of family that newcomers had. Strong ties that are developed with existing networks in Canada (in some cases with new acquaintances that are met upon arrival) became, over time, akin to a 'family member'. As explained by Holstein and Gubrium (1999), "the essence of family is found in the way family is used, not in conventional or idealized social forms" (p.7). "Biological, moral and legal kinship terms...do not communicate meaning in terms of commitment, caring, and obligation" (Smith, 1993 as cited in Holstein \& Gubrium, 1999, p.6-7). As such, households should not be conceptualized as homogenous entities; families are fluid, inseparable from internal dynamics, and changing depending on needs (Creese et al., 2008). This finding demonstrates the importance of real lived experiences of identity which inform who is family.

Yet, as noted by the Social Planning Council of Ottawa (2010), Canadian institutions rely on the nuclear model which prescribes the involvement of parents at school, in the integration of children and even in the justice system. This 'intact-nuclear-family-model' does not always hold or reflect newcomer realities. In many newcomer families, multiple members, including extended family may play a role in the care or rearing of the child. Family transformations resulting from immigration entail shifts in decision-making powers and roles of support (Falicov, 2007). In cases of separated/multi-local families, it should not be assumed that the 'parental authority' lies with the parent or that its locus is in the household (Bernhard et al., 2005). Most importantly, Bernhard et al. (2005) emphasize that these diverse family forms "are not 'deficient' or 'defective' family units 
simply because they do not conform to the traditional model of the nuclear single-site family" (p.2). Research shows family/social support is the most important indicator of success for settlement and integration. Policy at all institutional levels should support the participation of an extended family member with a lasting relationship to the child. To reflect the conceptualization of family of newcomers themselves, important family and social supports should be valued and upheld by institutions. This measure will strengthen newcomer families and empower them.

Therefore, newcomer families require policies with an inclusive and flexible definition of the family unit. The Ontario Council of Agencies Serving Immigrants has expressed this position:

\begin{abstract}
"Canadians recognize the immeasurable importance of parents and grandparents and other extended family members in our lives, in our families and our communities. It is time for the government to also recognize and expand our understanding of family, in a world where extended family networks are essential to personal and community success. For new immigrants, they are part of a support network that is critical to make a successful adjustment to a new country." (OCASI, 2011, p.1)
\end{abstract}

It is our final recommendation that policy-makers at all levels of government, and in this case specifically in IRCC settlement policy, adopt the definition of 'chosen' family. It is crucial that newcomers themselves be allowed to define who they consider as family, perhaps not in terms of a specific kinship position (Daniel, 2005), but in terms of sharing/providing support. The 'chosen' family is the family as defined by the newcomer client and must be the benchmark for a Family Approach settlement policy.

Recommendation 5: Adopt an inclusive and flexible definition of family across settlement policy 


\section{Overview}

This position paper seeks to inform an evidenced-based service approach for IRCC policymakers in the settlement sector. A sincere effort was made to translate academic literature and research findings from the ITIF project into practical format for uptake at the policy level. The perspective of service provider organizations was incorporated through consultations with two reputable, multi-local settlement organizations in the Greater Toronto Area. Their participation strengthens this paper and complements IRCC's priority to build a client-centered sector.

Academic research and ITIF project findings demonstrated that newcomers' settlement experiences are deeply intertwined with the family. Yet, immigration policy and IRCC-funded settlement services continue to operate using an individualized framework. In this paper, we made the case for paying attention to families. We argued for the implementation of a Family Approach in settlement services building on three policy orientations:

- to complicate the conceptualization of newcomers as individuals

- to incorporate a holistic family approach in settlement

- to draw on empirical evidence that supports settlement workers' first-hand observations

Finally, through consultations with partners, we devised five practical recommendations for the implementation of a Family Approach in IRCC-funded settlement services, program design, data management and collection, and operational definitions:

1. Implement a Family Approach framework/methodology in the Needs Assessment and Referral program and the Information and Orientation program description and service agreement

2. Add a section on the family in the Needs Assessment and Referral iCARE reporting platform, with markers to identify family needs and social capital measures 
3. Coordinate settlement needs at the family level by linking the family members' files in iCARE to reflect the inter-connectedness of needs

4. Enhance the recognition of family needs through the expansion of para-counseling support services, inclusive family programs, and social networking programs

5. Adopt an inclusive and flexible definition of family across settlement policy

At the heart of the ITIF project and ultimately this paper is the goal of improving settlement services available to newcomers. We trust that the government has every intention to do the same and we encourage that a course of action towards the implementation of a Family Approach be taken accordingly.

"If I get the opportunity to talk to an official I will... [say that] the route for the success of Canada is family. If an immigrant family is a broken one, the whole Canadian system ultimately ends up being broken. The base for the success of the country is a family" [...] "if there are so many successful families, there would definitely be a successful Canada" [...] "That same policy that invited them must support them."

[PARTICIPANT \#23] 


\section{Conclusion}

The findings of the ITIF project as well as a review of the academic literature demonstrate that there is a strong consensus for a family approach in the settlement sector services. However, there is a 'knowledge gap', where academic findings have not been translated into useful tools to inform practice in the sector. This research project used Knowledge Translation to determine how academic research on the importance of situating immigrants within families can be transferred into a practical Family Approach framework for settlement services and challenge the current individualistic structure of program design, funding and policy. To achieve this, a partnership with two large settlement organizations was secured and consultations with practitioners ensured relevance of the KT. The project ultimately seeks to improve settlement services for newcomers by influencing needs assessments, program design, outcome measurement and policy in the settlement sector to reflect the interconnectedness of newcomer needs with a web of social relations. The final product is a position paper which outlines five key recommendations for the implementation of a Family Approach. The position paper is being presented to IRCC policy-makers.

Shields and Evans (2012) write that "KM/KT is a process, not an end-state... as with anything human, it is far from perfect but... it certainly can be successful" (p.268). This is an ambitious project, nonetheless, it was done with humility since "it is rare that any one research report makes a difference but rather it is the ongoing contacts and dialogue around policy issues and research evidence that has a penetrating impact on policy thinking" (Shields \& Evans, 2012, p.267). Hopefully, this research project which seeks "to balance research excellence with relevance" (Frenk, 1992 as referenced in Shields \& Evans, 2012, p.253) is a starting point to inspire more work. 


\section{Appendix 1 - Preliminary questions for first consultation meeting}

\section{Current Settlement Programs funded by IRCC}

Which of your settlement programs are funded by IRCC?

\section{Settlement Program Objectives}

Do any of these programs have the objective of expanding the newcomers' social network?

Do any of these programs encourage group participation (newcomer can bring a family member/friend)?

\section{Outcome requirement to report on to IRCC}

What are the program outputs you have to report on to IRCC? How are these outputs measured? How are immigrant families reflected (or not) in this type of output measurement?

- If a family show up for a newcomer needs assessment, how is this recorded (or not)?

Do settlement workers measure other outputs?

\section{Relationship with IRCC in terms of program design}

Do you have the possibility of suggesting changes to IRCC in terms of program design?

Do you have the possibility of suggesting changes to IRCC in terms outcome measurement?

How could this research be used to negotiate with IRCC to propose changes?

\section{Newcomer Needs Assessment}

Newcomers' needs are interconnected with their social network/family. How is this addressed in a needs assessment? (Ex. single mother of three school-age children seeking employment)

How could the needs assessment and outcome measurement better capture the interconnectedness of newcomer needs? What changes could be made?

- On IRCC's part

- On the organization's part, regardless of IRCC

What are the challenges to achieving this?

\section{MRP format}

- Is a position paper (approx. 15 pages) the best format for suggesting practical changes?

- How do you imagine this document?

- Are there internal documents that would be useful for me to have to write this MRP? 


\section{Appendix 2 - Executive Summary (English Version)}

Funding from IRCC to Service Provider Organizations throughout Canada (except Quebec) has enabled 412,390 newcomers to access settlement services in the last year (IRCC, 2017d). Stakeholders of the settlement sector agree that the settlement outcomes of immigrants "will have significant and long-term impacts on the cohesion and strength of Canadian society" (OCASI, 2011, p.2).

IRCC, as one of the largest stakeholders of the successful integration of immigrants, has expressed its commitment to working with immigrant serving agencies "to build a client-centered approach" for program design and delivery of settlement services (OCASI, 2010, p.4). At the same time, IRCC values rigorous academic research focused on immigration and settlement to better inform evidence-based policy.

Upon close examination of settlement policy, we find that there is a significant gap between recent empirical findings and current settlement service models. IRCC-funded settlement services conceptualize and thereby treat immigrants as discrete individual units. However, empirical studies demonstrate that a fundamental dimension of the settlement process is experienced at the relational, social, and family levels. The Integration Trajectories of Immigrant Families project unveils new findings on the family as a key unit of analysis for settlement. This evidence provides a unique opportunity to improve the current settlement service framework.

This position paper directly targets decision-makers for settlement policy. Three over-arching orientations for action were identified:

- Need to complicate the current conceptualization of immigrants as individuals

- Need to incorporate a holistic family approach in settlement policy and services 
- Need to draw on empirical evidence that recognizes and lends support to settlement workers' first-hand observations and experience-driven insight

Through consultations with two prominent settlement agencies in the Greater Toronto Area, empirical knowledge combined with settlement practitioner observations were translated into a holistic evidence-based, client-centered framework for settlement services: A Family Approach.

Incorporating a Family Approach in the settlement sector implies a re-thinking of the framework behind program design, policy, settlement funding, outcome measurement, and service delivery, which are currently using an individualistic approach. We urge IRCC to adopt five key practical recommendations for the implementation of a Family Approach in settlement services:

1. Inscribe the Family Approach as an explicit framework/method of the Needs Assessment and Referral program and the Information and Orientation program service agreements

2. Add a section on the family in the Needs Assessment and Referral iCARE reporting platform, with markers to identify family needs

3. Coordinate settlement needs at the family level by linking family members' files in iCARE to reflect the inter-connectedness of needs and collect social capital measures

4. Enhance the recognition of family needs through the expansion of para-counselling support services, inclusive family programs, and social networking programs

5. Adopt an inclusive and flexible definition of family across settlement policy

The purpose of these recommendations is to empower immigrant families of all forms to acquire social supports for settlement and to provide both settlement organizations and IRCC with a family-level representation of newcomer settlement needs for future evidence-based policymaking. Incorporating a Family Approach would result in services that better address newcomers' settlement realities by taking into account the family, in all its forms, and to develop prevention of domestic violence and inter-generational conflict. 


\section{Appendix 3 - Résumé (Version Française)}

Le financement que l'IRCC octroie aux organismes prestataires de services d'établissement pour nouveaux arrivants à travers le Canada (sauf Québec) a permis de desservir pas moins de 412,390 nouveaux arrivants l'an dernier (IRCC, 2017d). Les acteurs du milieu sont unanimes pour dire que l'établissement des immigrants aura des conséquences de longue haleine sur la cohésion de la société Canadienne.

L'IRCC, en tant que principal mandataire pour la réussite de l'établissement des nouveaux arrivants, a fait connaître son engagement à travailler en collaboration avec les organismes dans le but de développer une approche de service centrée sur les besoins de la clientèle (OCASI, 2010). Du même coup, l'IRCC valorise la recherche académique rigoureuse dans le domaine de l'immigration et de l'établissement pour concevoir ses politiques.

Cependant, nous constatons qu'il y a un vaste écart entre les récentes découvertes des chercheurs et l'approche de service actuellement en place dans le secteur. Les programmes d'intégration et d'établissement subventionnés par l'IRCC utilisent une approche de service qui définit le nouvel arrivant comme unité individuelle. Cependant, les chercheurs démontrent plutôt que la dimension relationnelle, sociale et familiale est au cœur de l'expérience de l'établissement. Un projet de recherche novateur auprès de nouveaux arrivants révèle que l'unité d'analyse de la famille est indispensable pour le domaine. Cette recherche offre une opportunité exceptionnelle afin d'adapter et de faire progresser l'approche de service du secteur.

Le présent rapport s'adresse directement aux hauts responsables des politiques du secteur de l'établissement de l'IRCC. Trois principales démarches d'opération ont été identifiées:

- Revoir l'approche de service individualiste actuelle 
- Incorporer une approche familiale holistique aux services et politiques d'intégration

- Utiliser la recherche académique qui reconnaît et soutien les connaissances de première ligne des intervenants et l'expertise des professionnels

À travers une série de consultations avec deux influentes agences d'intégration du secteur du Grand Toronto, les données probantes en recherche combinées à l'expertise des professionnels d'organismes ont été traduites en une nouvelle approche de service holistique, fondée et centrée sur les besoins des nouveaux arrivants: une Approche Familiale.

L'adoption d'une Approche Familiale implique une révision de la structure actuelle déterminant les politiques, le financement, la compilation des données, et l'offre de service des programmes d'intégration, qui s'appuie sur une approche individuelle. Nous suggérons fortement à l'IRCC d'adopter cinq recommandations clés pour l'implantation de l'Approche Familiale:

1. Désigner l'Approche Familiale comme étant un aspect fondamental du cadre et de la méthodologie du service d'Évaluation des Besoins et d'Aiguillage ainsi que du service d'Information et d'Orientation

2. Ajouter une section sur la famille dans l'Évaluation des Besoins et d'Aiguillage du logiciel Immigration - Environnement de Déclarations d'Ententes de Contribution (IEDEC), incluant des indicateurs de besoins familiaux

3. Coordonner les besoins au niveau familial en joignant les dossiers des membres de la famille dans IEDEC pour refléter les besoins interrelationnels et recueillir des données

4. Accroître la reconnaissance des besoins familiaux en ajoutant des Services de Soutien de ‘counseling temporaire', des programmes familiaux inclusifs et du réseautage social

5. Adopter une définition inclusive et flexible de la famille à travers les politiques du secteur L'objectif de ces recommandations est d'accroître le bien-être et la résilience des familles immigrantes en facilitant l'établissement de divers soutiens sociaux. De plus, elles permettent 
d'optimiser la collecte de données familiales et la représentation des besoins familiaux, qui sera autant valable pour les organismes que pour l'IRCC afin d'améliorer les politiques et programmes d'établissements futurs. Enfin, l'Approche Familiale permettrais d'assurer des services d'établissement qui reflètent la réalité des nouveaux arrivants dans un contexte familial, sous toutes ses formes, et de développer davantage la prévention de la violence conjugale et des conflits intergénérationnels. 


\section{References}

Ali, M., Valade, M., \& Dargy, T. (forthcoming). Families' roles in immigration and settlement. In H. Bauder (Ed.), Migration is a family affair. Vancouver, BC: UBC Press.

Baldassi, C. (2007). DNA, Discrimination and the Definition of Family Class: M.A.O. v. Canada (Minister of Citizenship and Immigration). Journal of Law and Social Policy, 21, 5-30.

Bauder, H. (Ed.). (forthcoming). Migration is a family affair. Vancouver, BC: UBC Press.

Bergeron, J., \& Potter, S. (2006). Family members and relatives: An important resource for newcomers' settlement? Canadian Issues, 2006(Spring), 76-80.

Bernhard, J. K., Goldring, L., Landolt, P., \& CERIS. (2005). Transnational, multi-local motherhood: Experiences of separation and reunification among Latin American families in Canada. Working Paper Series. CERIS: The Ontario Metropolis Center.

Boyd, M. (1989). Family and personal networks in international migration: Recent developments and new agendas. International Migration Review, 23(3), 638-670.

Bragg, B., \& Wong, L. L. (2016). "Cancelled Dreams": Family Reunification and Shifting Canadian Immigration Policy. Journal of Immigrant \& Refugee Studies, 14(1), 46-65.

Brouwer, A. (2004). Permanent protection: Why Canada should grant permanent residence automatically to recognized refugees. Toronto, ON: Public Justice Resource Centre.

Burr, K., Citizenship and Immigration Canada. (2011). Local Immigration Partnerships: Building Welcoming and Inclusive Communities through Multi-Level Governance. Horizons Policy Research Initiative. Retrieved from Pathways to Prosperity Canada publications website: http://p2pcanada.ca/files/2011/10/Local-Immigration-PartnershipsBuilding-Welcoming-and-Inclusive-Communities.pdf

Canada, Parliament. House of Commons. Standing Committee on Citizenship and Immigration. (2010). Report on Best Practices in Settlement Services. $40^{\text {th }}$ Parl., $3^{\text {rd }}$ sess. Retrieved from the Parliament of Canada website: http://www.ourcommons.ca/DocumentViewer/en/40-3/CIMM/report-2/

Canada, Parliament. House of Commons. Standing Committee on Citizenship and Immigration. (2017). Report on Family Reunification. $42^{\text {nd }}$ Parl., $1^{\text {st }}$ sess. Retrieved from the Parliament of Canada website: https://www.ourcommons.ca/DocumentViewer/en/42$\underline{1 / \mathrm{CIMM} / \text { report-8/ }}$ 
Citizenship and Immigration Canada (CIC). (2011). Evaluation of the Immigrant Settlement and Adaptation Program (ISAP). Retrieved from IRCC program evaluations website: http://www.cic.gc.ca/english/pdf/research-stats/evaluation-isap2011.pdf

Citizenship and Immigration Canada (CIC). (2016). Terms and Conditions of Settlement Programs Contribution Agreement. Retrieved from IRCC Program Terms and Conditions website: http://www.cic.gc.ca/english/transparency/documents/pdf/SettlementProgramEN.pdf.

Cooke, T. J. (2008). Migration in a family way. Population, Space and Place, 14(4), 255-265.

Cottrell, B. \& Vanderplaat, M. (2011). My kids want to eat pork: Parent-teen conflicts in immigrant families. In Tatsoglou, E. \& Jaya, S.P. (Eds.), Immigrant Women in Atlantic Canada: Challenges, Negotiations, and Re-Constructions (267-296). Toronto, ON: Canadian Scholars' Press.

Creese, G. L., Dyck, I., \& McLaren, A. T. (2002). Reconstituting the family: Negotiating immigration and settlement. Research on Immigration and Integration in the Metropolis (RIIM) \& Vancouver Centre of Excellence. Vancouver, BC: Simon Fraser University.

Creese, G.L., Dyck, I., \& McLaren, A.T. (2008). The 'flexible' immigrant? Human capital discourse, the family household and labour market strategies. Journal of International Migration and Integration, 9(3), 269-288.

Creswell, J.W. (2013). Research design: Qualitative, quantitative, and mixed methods approaches, p. 1-24. Thousand Oaks, CA: Sage.

Daniel, D. (2005). The debate on family reunification and Canada's immigration act of 1976. American Review of Canadian Studies, 35(4), 683-703.

DeShaw, R. (2006). The history of family reunification in Canada and current policy. Canadian Issues, 2006(Spring), 9-14.

Ebaugh, H. R., \& Curry, M. (2000). Fictive kin as social capital in new immigrant communities. Sociological Perspectives, 43(2), 189-209.

Falicov, C.J. (2007). Working with transnational immigrants: Expanding meanings of family, community, and culture. Family Practices, 46(2), 157-171.

Frenk, J. (1992) Balancing relevance and excellence: Organizational responses to link research to with decision making. Social Science and Medicine, 35(11), 1397-1404.

Frideres, J.S. \& Madibbo, A. (2013). Building bridges: Immigrant, visible minority, and aboriginal families in the twenty-first century. In Cheal, D. J. \& Albanese, P. 
(Eds.) Canadian families today: New perspectives (Third ed.). Toronto, ON: Oxford University Press.

George, U. (2002). A needs-based model for settlement service delivery for newcomers to Canada. International Social Work, 45(4). 465-480.

Guruge, S., Shirpak, K. R., Hyman, I., Zanchetta, M., Gastaldo, D., \& Sidani, S. (2010). A metasynthesis of post-migration changes in marital relationships in Canada. Canadian Journal of Public Health, 101(4), 327-331.

Hogg, M. A., \& Abrams, D. (1999). Social identifications: A social psychology of intergroup relations and group processes. London and New York: Routledge.

Holstein, J., \& Gubrium, J. (1999). What is family? Marriage \& Family Review, 28(3), 3-20.

Hynie, M., Crooks, V. A., \& Barragan, J. (2011). Immigrant and refugee social networks: Determinants and consequences of social support among women newcomers to Canada. Canadian Journal of Nursing Research, 43(4), 26-46.

Immigration and Refugee Protection Act (IRPA). (S.C. 2001, c.27). Section 12 (1). Accessed August 9, 2017. Retrieved from the Justice Laws website: http://laws.justice.gc.ca/eng/acts/i-2.5/page-4.html\#h-10

Immigration and Refugee Protection Regulations (IRPR). (SOR/2002 - 227). Part 7, Division 1, Section 117. Accessed August 9, 2017. Retrieved from the Justice Laws website: http://laws-lois.justice.gc.ca/eng/regulations/sor-2002-227/page-23.html\#h-68

Immigration and Refugee Protection Regulations (IRPR). (SOR/2015 - 77). Part 1, Division 1, Section 1(3). Accessed August 9, 2017. Retrieved from the Justice Laws website: http://laws-lois.justice.gc.ca/eng/regulations/sor-2002-227/page-23.html\#h-68

Immigration, Refugees and Citizenship Canada (IRCC). (2016). Annual Report to Parliament on Immigration 2016. Retrieved from the IRCC publications website: http://www.cic.gc.ca/english/resources/publications/annual-report-2016/index.asp

Immigration, Refugees and Citizenship Canada (IRCC). (2017a). Settlement Program - Themes and Priorities. Accessed August 9, 2017. Retrieved from the IRCC webpage: http://www.cic.gc.ca/english/department/grants-contributions-funding/settlementpriorities.asp

Immigration, Refugees and Citizenship Canada (IRCC). (2017b). Funding. Accessed August 9, 2017. Retrieved from the IRCC webpage: http://www.cic.gc.ca/english/department/grants-contributions-funding/index.asp 
Immigration, Refugees and Citizenship Canada (IRCC). (2017c). Community-Connections.

Accessed August 9, 2017. Retrieved from the IRCC webpage:

http://www.cic.gc.ca/english/newcomers/community-connections.asp

Immigration, Refugees and Citizenship Canada (IRCC). (2017d). Canada - Settlement Service Clients by Province/Territory of Settlement Provider Organization, Age Group, at Service and Fiscal Year April 2015 - June 2017 (see total for Apr 2016 - March 2017). Accessed August 9, 2017. Retrieved from the IRCC webpage (Settlement Service Clients - Monthly IRCC Updates): http://open.canada.ca/data/en/dataset/ba24ad39-2d68-4d49$\underline{85 \mathrm{~b} 4-\mathrm{ee} 13 \mathrm{c} 60 \mathrm{~b} 4 \mathrm{aa} 3}$

Kazemipur, A. (2006). The market value of friendship: Social networks of immigrants. Canadian Ethnic Studies Journal, 38(2), 47-71.

Kramer, D.M.E. (2002). From knowledge transfer to knowledge transformation: A manufacturing workplace intervention study. (Published Doctoral Dissertation). University of Toronto: Toronto ON, Canada. Retrieved from ProQuest Dissertations Publishing (Order No. NQ69258).

Kustec, S. (2006). Family versus individual immigration: A new analytical perspective. Canadian Issues, 2006(Spring), 17-20.

Kvale, S. (1995). The social construction of validity. Qualitative Inquiry, 1(1), 19-40

Lewis-Watts, L. (2006). Speaking with families from within the 'family class'. Canadian Issues, 2006(Spring), 81-84.

Locke, L., Silverman, S., and Spirduso, W. (2004). Reading reports of qualitative research-Critically. In Reading and understanding research (209-226). Thousand Oaks, CA, USA: Sage Publications.

Lynam, M. J. (1985). Support networks developed by immigrant women. Social Science \& Medicine, 21(3), 327-333.

Mackenzie, N., \& Knipe, S. (2006). Research dilemmas: Paradigms, methods and methodology. Issues in Educational Research, 16(2), 193-205.

Mukhtar, M., Dean, J., Wilson, K., Ghassemi, E., \& Wilson, D.H. (2016). "But many of these problems are about funds...": The challenges immigrant settlement agencies (ISAs) encounter in a suburban setting in Ontario, Canada. Journal of International Migration and Integration, 17(2), 239-408. 
Ontario Council for Agencies Serving Immigrants (OCASI). (2010). Framework for modernized settlement in practice: The OCASI vision. Retrieved from the OCASI publications website: $\underline{\text { http://ocasi.org/downloads/OCASI_ModernizedSettlement_September2010.pdf }}$

Ontario Council for Agencies Serving Immigrants (OCASI). (2011). OCASI position on family reunification. Retrieved from the OCASI publications website: http://www.ocasi.org/ocasi-position-family-reunification

Phan, M. B., Banerjee, R., Deacon, L., \& Taraky, H. (2015). Family dynamics and the integration of professional immigrants in Canada. Journal of Ethnic and Migration Studies, 41(13), 2061-2080.

Philips, J. (2016). Racialized risks, queer threats: Refugee experiences of 'sanctuary' in the city of Toronto (Unpublished Master's Thesis). Ryerson University: Toronto, ON, Canada. Retrieved from Ryerson University Library Digital Repository.

Rose, D., Carrasco, P., \& Charbonneau, J. (1998). The role of "weak ties" in the settlement experiences of immigrant women with young children: The case of Central Americans in Montréal. Working Paper Series. CERIS-Toronto Centre of Excellence for Research on Immigration and Settlement.

Salaff, J. W., \& A. Greve. (2004). Can Chinese Women's Social Networks Migrate? Women's Studies International Forum, 27(2), 149-162.

Satzewich, V. (1993). Migrant and immigrant families in Canada: State coercion and legal control in the formation of ethnic families. Journal of Comparative Family Studies, 24(3), 315-338.

Shields, J., \& Evans, B. (2012). Building a policy-oriented research partnership for knowledge mobilization and knowledge transfer: The case of the Canadian Metropolis Project. Administrative Science, 2(4), 250-272.

Shields, J., Preston, V., Richmond, T., Sorano, Y., Gasse-Gates, E., Douglas, D., Campey, J., Johnston, L. (2015). Knowledge Mobilization/Transfer and immigration policy: Forging space for NGOs-the case of CERIS-The Ontario Metropolis Centre. Journal of International Migration and Integration, 16(2), 265-278.

Simich, L., Beiser, M., \& Mawani, F. (2003). Social support and the significance of shared experience in refugee migration and resettlement. Western Journal of Nursing Research, $25(7), 872-891$. 
Simich, L., Beiser, M., Stewart, M., \& Mwakarimba, E. (2005). Providing social support for immigrants and refugees in Canada: Challenges and directions. Journal of Immigrant and Minority Health, 7(4), 259-268.

Smith, D. E. (1993). The standard North American family: SNAF as an ideological code. Journal of Family Issues, 14(1), 50-65.

Smith, H.A. (2007). Public administration scholars as a source of knowledge for federal practitioners: Barriers to communications in the federal environment (Published Doctoral Dissertation), George Washington University: Washington, DC, USA. Retrieved from ProQuest Dissertations Publishing (Order No. 3250604).

Social Planning Council of Ottawa. (2010). Immigrant children, youth and families: A qualitative analysis of the challenges of integration. Retrieved from the Social Planning Council of Ottawa publications website: https://www.spcottawa.on.ca/sites/all/files/pdf/2010/Publications/Immigrant-FamilyReport-English.pdf

Statistics Canada. (2005). Longitudinal Survey of Immigrants to Canada: Portrait of Early Settlement Experiences. Ottawa: Minister of Industry. (www.statcan.ca)

Strasser, E., Kraler, A., Bonjour, S., \& Bilger, V. (2009). Doing family. Responses to the constructions of 'the migrant family' across Europe. History of the Family, 14(2), 165176.

Straus, S., Tetroe, J., \& Graham, I. (2009). Defining knowledge translation. Canadian Medical Association Journal, 181(3), 165-168.

Telegdi, A. (2006). Family Reunification: The key to successful integration. Canadian Issues, 2006(Spring), 94-96.

Toronto Public Health (prepared by Tate, E.). (2011). Family Separation and Reunification of Newcomers in Toronto. Retrieved from the Toronto Public Health website: https://www1.toronto.ca/city_of_toronto/toronto_public_health/healthy_communities/me ntal_health/family_separation/files/pdf/fsr_newcomers.pdf

Toronto Public Health. (2014). How Settlement Workers Can Support Clients Affected By Family Separation and or Reunification. Retrieved from the Toronto Public Health website: https://www1.toronto.ca/city_of_toronto/toronto_public_health/healthy_communities/me ntal_health/family_separation/files/pdf/guide_for_settlement_agencies.pdf

Vanderplaat, M., Ramos, H. \& Yoshida, Y. (2012). What do Sponsored Parents and Grandparents Contribute? Canadian Ethnic Studies, 44(3), 79-96. 
Wang, L., \& Handy, F. (2014). Religious and secular voluntary participation by immigrants in Canada: How trust and social networks affect decision to participate. VOLUNTAS: International Journal of Voluntary and Nonprofit Organizations, 25(6), 1559-1582.

Wayland, S. V., Law Commission of Canada, \& Community Foundations of Canada. (2006). Unsettled: legal and policy barriers for newcomers to Canada. Retrieved from the Canadian Metropolis publications website: http://canada.metropolis.net/publications/pdfs/pf_9_ENG_Immigration.pdf

Weston, K. (1991). Families we choose: Lesbians, gays, kinship. New Yok, NY: Columbia University Press.

Zhu, Y. (2016). Immigration policy, settlement service, and immigrant mothers in neoliberal Canada: A feminist analysis. Canadian Ethnic Studies, 48(2), 143-156. 